\title{
Long-term assessment of the CALIPSO Imaging Infrared Radiometer (IIR) calibration and stability through simulated and observed comparisons with MODIS/Aqua and SEVIRI/Meteosat
}

\author{
Anne Garnier ${ }^{1,2}$, Noëlle A. Scott ${ }^{3}$, Jacques Pelon ${ }^{4}$, Raymond Armante ${ }^{3}$, Laurent Crépeau $^{3}$, Bruno Six $^{5}$, and \\ Nicolas Pascal ${ }^{6}$ \\ ${ }^{1}$ Science Systems and Applications, Inc., Hampton, VA 23666, USA \\ ${ }^{2}$ NASA Langley Research Center, Hampton, VA 23681, USA \\ ${ }^{3}$ Laboratoire de Météorologie Dynamique, Ecole Polytechnique-CNRS, 91128 Palaiseau, France \\ ${ }^{4}$ Laboratoire Atmosphères, Milieux, Observations Spatiales, UPMC-UVSQ-CNRS, 75252 Paris, France \\ ${ }^{5}$ Université Lille 1, AERIS/ICARE Data and Services Center, 59650 Lille, France \\ ${ }^{6}$ Hygeos, AERIS/ICARE Data and Services Center, 59650 Lille, France
}

Correspondence to: Anne Garnier (anne.garnier@latmos.ipsl.fr)

Received: 13 October 2016 - Discussion started: 14 November 2016

Revised: 6 March 2017 - Accepted: 21 March 2017 - Published: 13 April 2017

\begin{abstract}
The quality of the calibrated radiances of the medium-resolution Imaging Infrared Radiometer (IIR) onboard the CALIPSO (Cloud-Aerosol Lidar and Infrared Pathfinder Satellite Observation) satellite is quantitatively evaluated from the beginning of the mission in June 2006. Two complementary "relative" and "stand-alone" approaches are used, which are related to comparisons of measured brightness temperatures and to model-to-observations comparisons, respectively. In both cases, IIR channels $1(8.65 \mu \mathrm{m}), 2(10.6 \mu \mathrm{m})$, and $3(12.05 \mu \mathrm{m})$ are paired with the Moderate Resolution Imaging Spectroradiometer (MODIS)/Aqua Collection 5 "companion" channels 29, 31, and 32, respectively, as well as with the Spinning Enhanced Visible and Infrared Imager (SEVIRI)/Meteosat companion channels IR8.7, IR10.8, and IR12, respectively. These pairs were selected before launch to meet radiometric, geometric, and space-time constraints. The prelaunch studies were based on simulations and sensitivity studies using the 4A/OP radiative transfer model and the more than 2300 atmospheres of the climatological Thermodynamic Initial Guess Retrieval (TIGR) input dataset further sorted into five air mass types. Using data from over 9.5 years of on-orbit operation, and following the relative approach technique, collocated measurements of IIR and of its companion channels have been compared at all latitudes over ocean, during day and night,
\end{abstract}

and for all types of scenes in a wide range of brightness temperatures. The relative approach shows an excellent stability of IIR2-MODIS31 and IIR3-MODIS32 brightness temperature differences (BTDs) since launch. A slight trend within the IIR1-MODIS29 BTD, that equals $-0.02 \mathrm{~K} \mathrm{yr}^{-1}$ on average over 9.5 years, is detected when using the relative approach at all latitudes and all scene temperatures. For very cold scene temperatures (190-200 K) in the tropics, each IIR channel is warmer than its MODIS companion channel by $1.6 \mathrm{~K}$ on average. For the stand-alone approach, clear sky measurements only are considered, which are directly compared with simulations using 4A/OP and collocated ERAInterim (ERA-I) reanalyses. The clear sky mask is derived from collocated observations from IIR and the CALIPSO lidar. Simulations for clear sky pixels in the tropics reproduce the differences between IIR1 and MODIS29 within $0.02 \mathrm{~K}$ and between IIR2 and MODIS31 within $0.04 \mathrm{~K}$, whereas IIR3-MODIS32 is larger than simulated by $0.26 \mathrm{~K}$. The stand-alone approach indicates that the trend identified from the relative approach originates from MODIS29, whereas no trend (less than $\pm 0.004 \mathrm{~K} \mathrm{yr}^{-1}$ ) is identified for any of the IIR channels. Finally, using the relative approach, a yearby-year seasonal bias between nighttime and daytime IIRMODIS BTD was found at mid-latitude in the Northern Hemisphere. It is due to a nighttime IIR bias as determined 
by the stand-alone approach, which originates from a calibration drift during day-to-night transitions. The largest bias is in June and July when IIR 2 and IIR3 are warmer by $0.4 \mathrm{~K}$ on average, and IIR 1 is warmer by $0.2 \mathrm{~K}$.

\section{Introduction}

The Cloud-Aerosol Lidar and Infrared Pathfinder Satellite Observation (CALIPSO) satellite (Winker et al., 2010), launched in April 2006, includes a payload of three instruments, the Cloud-Aerosol Lidar with Orthogonal Polarization (CALIOP), a visible wide-field camera, and the Imaging Infrared Radiometer (IIR). The IIR was built in France by the Centre National d'Études Spatiales (CNES), the Société d'Études et de Réalisations Nucléaires (SODERN), and Institut Pierre Simon Laplace (IPSL) (Corlay et al., 2000). It includes three spectral bands in the thermal infrared atmospheric window, at $8.65 \mu \mathrm{m}$ (IIR1), $10.6 \mu \mathrm{m}$ (IIR2), and $12.05 \mu \mathrm{m}$ (IIR3) with bandwidths of $0.85,0.6$, and $1 \mu \mathrm{m}$, respectively. These three channels were chosen to optimize retrievals of ice cloud properties in synergy with collocated observations from the CALIOP lidar (Garnier et al., 2012, 2013).

It is now well recognized by the international community that to be fully useful for climate and meteorological applications, satellite observations require quality control during the instrument's lifetime. Indeed, any systematic error or spurious trend not identified in the calibrated radiances may induce artifacts in the retrieved variables. In the mid-1990s, the NOAA/NASA Pathfinder Program and, later in 2005, the Global Space-based Inter-Calibration System (GSICS) initiated international collaborative efforts to improve and harmonize the quality of observations from operational weather and environmental satellites in order to create climate data records (e.g., Goldberg et al., 2011). A recent update on the GSICS vision is given in a 2015 World Meteorological Organization (WMO) report (GSICS, 2015).

In this paper, IIR observations since launch are monitored and characterized using two complementary approaches, which are the heritage of the processing of numerous years of satellite radiances for the restitution of climate variables (Chédin et al., 1985, and papers following on similar topics referenced and regularly updated at http://ara.abct.lmd. polytechnique.fr/index.php?page=publications). The monitoring of observational and computational biases or trends over long periods of time started with the NOAA/NASA TIROS Operational Vertical Sounder (TOVS) Pathfinder Program (Scott et al., 1999). Since then, it has been implemented for more recent hyperspectral sounders, namely the Atmospheric Infrared Sounder (AIRS) on-board the Aqua satellite since 2003, and since 2007 for the Interféromètre Atmosphérique de Sondage Infrarouge (IASI) on the MetOpA and
MetOpB satellites in cooperation with CNES (e.g., Jouglet et al., 2014) within the frame of its GSICS activities.

The first approach, called the "relative" approach, is based on a channel to channel intercomparison of radiances, further converted into equivalent brightness temperatures, with collocated measurements in companion channels of companion instruments under controlled conditions. The relative approach, sometimes referred to as the "inter-channel" or "inter-calibration" approach, was initially developed in a geostationary-low Earth orbit (GEO-LEO) combination for the calibration of Meteosat-1, based on space and time collocations with TOVS on the NOAA TIROS-N series (Bériot et al., 1982). The second approach, called the "stand-alone" approach, is based on comparisons between measured and simulated brightness temperatures for each companion channel of each companion instrument. The two approaches are complementary: the inter-calibration approach studies the behavior of one channel relative to its companion regardless of the underlying clear or cloudy scene and therefore allows for the study of a wide range of brightness temperatures. The standalone approach screens each channel of each instrument, individually, for clear sky scenes and helps to identify which channel deviates from the other(s). In this study, the clear sky mask is derived from collocated observations from the IIR and CALIOP.

The IIR companion instruments chosen for this study are the Moderate Resolution Imaging Spectroradiometer (MODIS) on-board Aqua and the Spinning Enhanced Visible and Infrared Imager (SEVIRI) on-board the geostationary second generation satellites Meteosat 8, 9, and 10. Both the MODIS and SEVIRI instruments, in operation since 2002 and 2004, respectively, include medium-resolution spectral bands similar to IIR channels.

An assessment of IIR radiances after 9.5 years of nearly continuous operation is presented, thereby updating the first results published in Scott (2009). This paper presents a brief description of the IIR instrument in Sect. 2, with prelaunch studies for the selection of IIR companion instrument and channels identified in Sect. 3, and the implementation of the relative and stand-alone approaches described in Sect. 4. Results and findings from the relative and the stand-alone approaches are presented in Sect. 5 and Sect. 6, respectively, and our assessment is summarized in the last section.

\section{The IIR/CALIPSO instrument}

The entire CALIPSO payload flies in a near-nadir, downlooking configuration, with a $0.3^{\circ}$ angle off-nadir in the forward direction. The off-nadir angle was increased to $3^{\circ}$ at the end of November 2007 to reduce specular reflections from horizontally oriented ice crystals in CALIOP observations (Hu et al., 2009). The IIR instantaneous field of view is $\pm 2.6^{\circ}$ or $64 \times 64 \mathrm{~km}$ on the ground, with $1 \mathrm{~km}$ size pixels. Thus, the viewing angles from nadir range from 0 to $3^{\circ}$ until Novem- 
ber 2007 and from 1 to $6^{\circ}$ after the CALIPSO payload pitch change, which is not expected to have any identifiable impact on the observations.

The IIR instrument (Corlay et al., 2000) includes three filters which are mounted on a rotating wheel for sequential acquisition within their respective spectral bands. The sensor is an uncooled microbolometer array (U3000) manufactured by Boeing and also implemented in the IASI instruments. IIR is regularly calibrated in flight using images of a temperaturemonitored warm blackbody source (at about $295 \mathrm{~K}$ ) and from cold deep space (about $4 \mathrm{~K}$ ) views. For each spectral band and for each pixel in the image, cold space views are used to determine the offset of the detection system, and images from the calibration blackbody source at known temperatures are used to retrieve the gains. The linearity of the detection system was verified before launch for scene temperatures ranging between 215 and $320 \mathrm{~K}$, and the gain retrieved from the warm calibration source is directly applied to calibrate the earth view images. Instrument spectral response functions (ISRFs) for each band were established by CNES before launch and are available upon request.

The overall calibration accuracy of the IIR measurement is specified to be better than $1 \mathrm{~K}$ in all channels. In-flight performances were assessed by CNES at the beginning of the mission (Trémas, 2006; Tinto and Trémas, 2008). The in-flight short-term gain stability was found to be better than $0.1 \mathrm{~K}$ of equivalent brightness temperature, except during the day-to-night transitions, during which the gain varies by up to $0.45 \mathrm{~K}$. The in-flight noise equivalent differential temperature (NedT) at $210 \mathrm{~K}$ was between 0.2 and $0.3 \mathrm{~K}$, similar to values measured before launch and better than the specified value of $0.5 \mathrm{~K}$. The NedT is of the order of $0.1 \mathrm{~K}$ at $250 \mathrm{~K}$.

The calibrated radiances are reported in the CALIPSO Version 1 IIR Level 1B products (Vaughan et al., 2015) available from the Atmospheric Science Data Center of the NASA Langley Research Center and at the AERIS/ICARE data center in France. They are resampled and registered on a $1 \mathrm{~km}$ resolution unique grid centered on the CALIOP ground track, at sea level, with a $69 \mathrm{~km}$ swath. The products are organized by separating the daytime and nighttime portions of an orbit to match the definition chosen for CALIOP and thereby facilitate synergetic analyses. Because the lidar is very sensitive to daylight background noise, the nighttime portion of the orbit is when the solar elevation angle at earth surface is less than $-5^{\circ}$ (Hunt et al., 2009).

\section{Method and prelaunch studies}

Both the relative and the stand-alone approaches require (i) companion instruments that offer the best possible spatiotemporal coincidences with IIR (primarily in order to see the same scenes simultaneously), and (ii) companion channels presenting close characteristics in terms of spectral coverage and spatial resolution. These constraints have oriented our choice towards two companion instruments: MODIS/Aqua and SEVIRI/Meteosat.

\subsection{Description of companion instruments}

MODIS/Aqua and SEVIRI/Meteosat in-flight performances have been extensively characterized (Xiong et al., 2015; EUMETSAT, 2007a, and references herein). The main instrumental characteristics of interest for comparison with IIR are summarized in Table 1 and are detailed in the following subsections.

\subsubsection{MODIS/Aqua}

The first companion instrument chosen for this study, MODIS/Aqua, includes three medium-resolution spectral bands in the thermal infrared window $(29,31$, and 32), with $1 \mathrm{~km}$ spatial resolution of interest for comparisons with IIR. Furthermore, both Aqua and CALIPSO, which is nominally positioned $73 \mathrm{~s}$ behind Aqua, have been flying in formation with other satellites of the A-Train (Stephens et al., 2002) since June 2006. The A-Train satellites follow a Sunsynchronous polar orbit at $705 \mathrm{~km}$ altitude with a $98.2^{\circ}$ inclination. CALIPSO measurements provide global coverage between $82^{\circ} \mathrm{N}$ and $82^{\circ} \mathrm{S}$. There is a 16-day repetition cycle, with an equator crossing time at about 13:35 local time. CALIPSO is controlled according to a customized grid shifted by $7 \mathrm{~min} 44 \mathrm{~s}$ local time from the nominal Worldwide Reference System-2 (WRS-2) grid used by Aqua, or $215 \mathrm{~km}$ eastward at the equator crossing. Due to the relative positions of the CALIPSO and Aqua satellites in the A-Train, the MODIS $2330 \mathrm{~km}$ swath always covers the IIR $69 \mathrm{~km}$ swath. The viewing angles for the MODIS pixels collocated with the IIR swath vary with latitude, as illustrated in Fig. 1, which shows histograms of MODIS viewing angles for six $30^{\circ}$ latitude bands for clear sky pixels over ocean in July 2014. The MODIS viewing angle is largest at the equator and ranges from 12 to $20^{\circ}$ at $0-30^{\circ}$ latitude in both hemispheres. It decreases progressively as latitude increases, to be mostly between 8 and $18^{\circ}$ at $30-60^{\circ}$ north and south and less than 12 at $60-82^{\circ} \mathrm{N}$. The pixels over ocean south of $60^{\circ} \mathrm{S}$ are actually north of about $70^{\circ} \mathrm{S}$ due the presence of the Antarctic continent, which explains why histograms at $82-60^{\circ} \mathrm{S}$ exhibit larger angles on average than those at $60-82^{\circ} \mathrm{N}$. These geometries of observation are accounted for in the simulations.

\subsubsection{SEVIRI/Meteosat}

Comparing IIR and MODIS/Aqua observations, both from the A-Train, ensures a very large sampling for statistical analyses. A complementary view is available through comparisons with SEVIRI on-board the geostationary second generation Meteosat satellites. SEVIRI provides radiometric data every $15 \mathrm{~min}$ in three spectral bands in the thermal infrared (channels IR8.7, IR10.8, and IR12) with a $3 \mathrm{~km}$ resolution at the sub-satellite point, which is at $0^{\circ}$ in both latitude and lon- 
Table 1. Main characteristics of the instruments and channels considered for this study.

\begin{tabular}{|c|c|c|c|}
\hline Instrument & IIR & MODIS & SEVIRI \\
\hline Platform & CALIPSO & AQUA & Meteosat 8,9 , and 10 \\
\hline Orbit & $\begin{array}{l}\text { LEO, A-Train } \\
73 \text { s behind AQUA }\end{array}$ & LEO, A-Train & GEO \\
\hline Temporal coverage & $\begin{array}{l}\text { Sun-synchr. 13:43 } \\
\text { 16-day repetition }\end{array}$ & $\begin{array}{l}\text { Sun-synchr. 13:35 } \\
\text { 16-day repetition }\end{array}$ & 15 min repeat cycle \\
\hline $\begin{array}{l}\text { Geographical } \\
\text { coverage for the study }\end{array}$ & $\begin{array}{l}\text { From WRS-2 grid } \\
\text { Lat.: } 82^{\circ} \mathrm{S}-82^{\circ} \mathrm{N} \\
\text { All longitudes }\end{array}$ & $\begin{array}{l}\text { WRS- } 2 \text { grid } \\
\text { Lat.: } 82^{\circ} \mathrm{S}-82^{\circ} \mathrm{N} \\
\text { All longitudes }\end{array}$ & $\begin{array}{l}\text { Lat.: } 10^{\circ} \mathrm{S}-10^{\circ} \mathrm{N} \\
\text { Long.: } 10^{\circ} \mathrm{W}-10^{\circ} \mathrm{E}\end{array}$ \\
\hline Spectral bands & $\begin{array}{l}\# 1: 8.2-9.05 \mu \mathrm{m} \\
\# 2: 10.35-10.95 \mu \mathrm{m} \\
\# 3: 11.6-12.6 \mu \mathrm{m}\end{array}$ & $\begin{array}{l}\# 29: 8.4-8.7 \mu \mathrm{m} \\
\# 31: 10.78-11.28 \mu \mathrm{m} \\
\# 32: 11.77-12.27 \mu \mathrm{m}\end{array}$ & $\begin{array}{l}\text { IR8.7: } 8.3-9.1 \mu \mathrm{m} \\
\text { IR10.8: } 9.8-11.8 \mu \mathrm{m} \\
\text { IR12: } 11.0-13.0 \mu \mathrm{m}\end{array}$ \\
\hline Swath & $69 \mathrm{~km}$ & $2330 \mathrm{~km}$ & Full disk \\
\hline Resolution & $1 \mathrm{~km}$ & $1 \mathrm{~km}$ & $3 \mathrm{~km}$ sub-satellite \\
\hline NedT & $\begin{array}{l}0.2-0.3 \mathrm{~K} @ 210 \mathrm{~K} \\
0.1 \mathrm{~K} @ 250 \mathrm{~K} \\
\text { Specification: }<0.5 \mathrm{~K}\end{array}$ & $\begin{array}{l}<0.025 \mathrm{~K} \\
\text { (Xiong et al., 2015) }\end{array}$ & $\begin{array}{l}<0.12 \mathrm{~K} \\
(\text { EUMETSAT, 2007a) }\end{array}$ \\
\hline
\end{tabular}

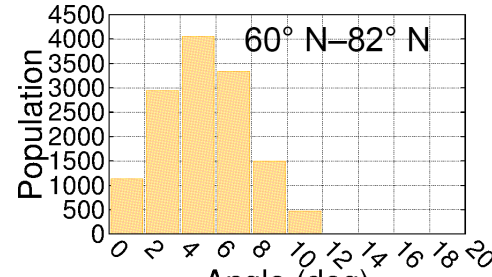

Angle (deg)

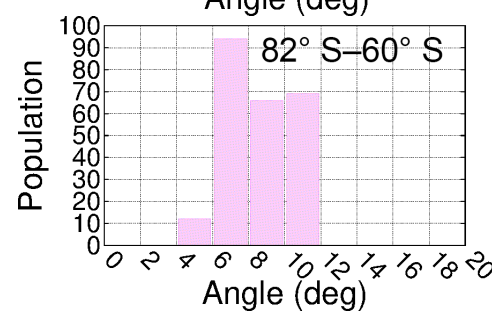

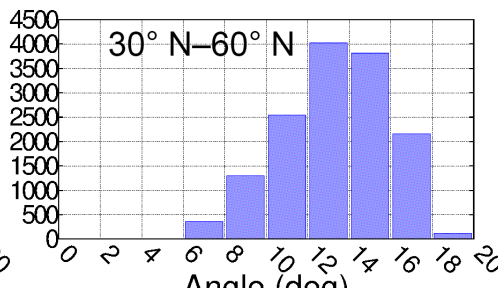

Angle (deg)

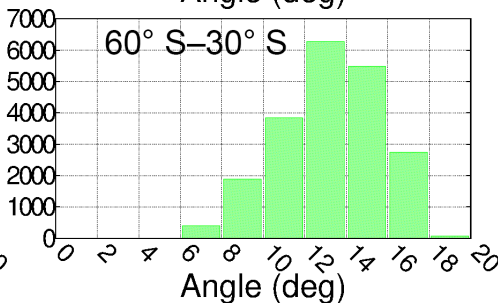

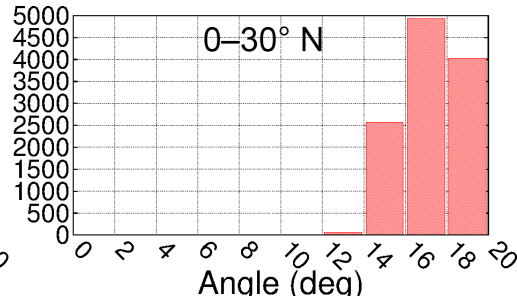

Angle (deg)

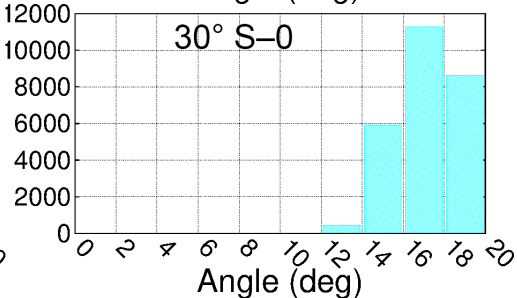

Figure 1. Histograms of MODIS viewing angles for clear sky pixels collocated with the IIR swath over ocean in July 2014 . Top row from left to right: $60-82,30-60,0-30^{\circ} \mathrm{N}$. Bottom row from left to right: $82-60,60-30$, and $30-0^{\circ} \mathrm{S}$.

gitude for the prime satellites. SEVIRI data are from three different prime geostationary satellites since June 2006: Meteosat 8 until 11 April 2007, then Meteosat 9 until 21 January 2013, and currently Meteosat 10. IIR and SEVIRI are best compared when SEVIRI viewing angles are smaller than $10^{\circ}$ to be close to IIR quasi-nadir observations, therefore, at latitudes between $10^{\circ} \mathrm{N}$ and $10^{\circ} \mathrm{S}$ and longitudes between $10^{\circ} \mathrm{W}$ and $10^{\circ} \mathrm{E}$.

\subsection{Selection of IIR, MODIS, and SEVIRI companion channels}

The IIR companion channels were chosen before launch among the various spectral channels of MODIS/Aqua and SEVIRI/Meteosat following a specific procedure. For each IIR channel, the selected MODIS or SEVIRI companion channel is the one that not only minimizes the brightness temperature differences (BTDs) with IIR, but also shows a similar sensitivity to the atmosphere and to the surface. This evaluation was conducted before launch by simulating the IIR and candidate companion channels using the forward radiative transfer model 4A (4A: Automatized At- 
mospheric Absorption Atlas) and more than 2300 atmospheres from the Thermodynamic Initial Guess Retrieval (TIGR) input dataset. MODIS/Aqua ISRFs can be retrieved from the MODIS Characterization Support Team website (http://mcst.gsfc.nasa.gov/calibration/parameters) and SEVIRI/Meteosat ISRFs from the EUMETSAT MSG Calibration website (http://www.eumetsat.int/website/home/Data/ Products/Calibration/MSGCalibration/index.html). In addition to the radiative coherence of the different pairs of channels, the quality of the comparisons performed for both the relative and the stand-alone approaches is based on the highest possible homogeneity of the observed surfaces and of the atmospheric optical paths. Differences in the spectral position and shape of the ISRFs can induce differences in surface emissivity. Furthermore, regardless of the perfection of the space-time collocation of the different instruments, the emitting surface may still be observed under different conditions. This is inherently related to the difference in the pixel size of each instrument as well as to the difference in the optical paths resulting from different viewing angles. Handling these differences is more difficult over land where altitude and nature of the ground contribute to enhance the inhomogeneity of the observed scenes. We have chosen to minimize these issues by restricting our study to observations over ocean. It is worthwhile to note that this choice allows a robust calibration assessment, in a wide range of brightness temperatures, at most latitudes and at any season, which is compatible with the aim of our study. Future work will include analyses at the highest latitudes, which are currently not examined because they are covered by ice, and analyses in extreme conditions of land surface temperatures. The simulated BTDs between IIR and the selected companion channels are shown in Sect. 3.2.3, after a brief description of the simulation model and of the auxiliary datasets in Sect. 3.2.1 and 3.2.2.

\subsubsection{The forward radiative transfer model: $4 \mathrm{~A}$}

The radiative transfer model used at all stages of this study is $4 \mathrm{~A} / \mathrm{OP}$, the operational version of $4 \mathrm{~A}$, adapted and maintained by NOVELTIS (http://4aop.noveltis.com/) in collaboration with CNES and Laboratoire de Météorologie Dynamique (LMD). The 4A model is a fast and accurate lineby-line (LBL) radiative transfer model initially developed at LMD (Scott and Chédin, 1981). As recalled in Anthony Vincent and Dudhia (2017), 4A was among the pioneer radiative transfer models to bypass LBL processing time by calculating once and for all a set of compressed look-up tables (LUTs) of monochromatic optical depths. These LUTs are generated by the nominal line-by-line STRANSAC model (Scott, 1974; Tournier et al., 1995) coupled to the Gestion et Étude des Informations Spectroscopiques Atmosphériques (GEISA) spectroscopic database. The 4A model generates transmittances, radiances, and jacobians (Chéruy et al., 1995) for any instrumental, spectral, and geometrical configuration (ground, airborne, and satellite).
The 4A model has a long history of validation within the frame of the international radiative transfer community. From the very beginning, most of the validation results have been extensively discussed in a number of intercomparison exercises and in particular during the Intercomparison of Transmittance and Radiance Algorithms (ITRA) working groups - 1983, 1985, 1988, and 1991 - of the International Radiation Commission (Chédin et al., 1988) and during the Intercomparison of Radiation Codes in Climate Models (ICRCCM) campaigns (Luther et al., 1988). More recently, observations from hyperspectral sounders such as AIRS and IASI have led to even more extensive validations, again within the frame of international observation campaigns or working groups, among them the International TOVS Study Conferences (ITSC) and the IASI Sounding Science Working Group (ISSWG). The 4A model is the official code selected by CNES for calibration and validation activities of the IASI, Merlin (https://merlin.cnes.fr), and MicroCarb (https://microcarb.cnes.fr) missions. A detailed description of the protocol and of the results of the interactive validation of GEISA and 4A/OP may be found in Armante et al. (2016).

Throughout the 9.5 years of IIR operation analyzed here, we have used a static version of 4A (2009 version) in order to avoid undesirable, however smooth, jumps. The LUTs were generated with STRANSAC coupled to the 2011 version of GEISA (Jacquinet-Husson et al., 2011). The 4A/OP model is in "down-up" mode, which means that the emission by the surface, the upwelling atmospheric radiation, and the reflection at the surface of the downwelling atmospheric radiation are taken into account, modulated by the emissivity or the reflectivity. The attenuated reflected downward radiance has been computed using a constant diffusivity factor. This approximation avoids computing a large number of downward radiances (and, above all, the computation of a large number of transmittance functions) corresponding to a large number of incident angles as well as integrating overall these angles. Such an approximation for the integration over the angle is usual in radiative transfer calculations: it was suggested as early as 1942 by Elsasser. Later on, tests on the validity of this approximation have been presented by Rodgers and Walshaw (1966), Liu and Schmetz (1988), Turner (2004), and many others. A value of $53^{\circ}$ is used here for the computation of the downwelling reflected radiances. Simulations are conducted for relevant MODIS and SEVIRI viewing angles (see Sect. 3.1 and Fig. 1), and IIR is considered as a nadir viewing instrument. Because the viewing angles are smaller than $20^{\circ}$, no specific dependence of the emissivity on the emission angle has been taken into account. A mean ocean surface emissivity equal to 0.98 for all the channels is used for these simulations. 


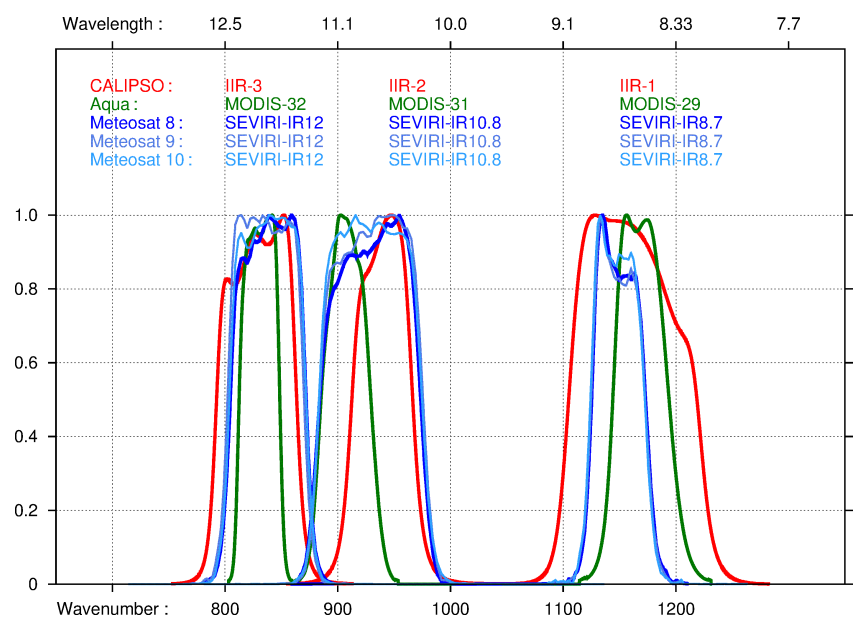

Figure 2. IIR/CALIPSO (red), MODIS/Aqua (green), and SEVIRI/Meteosat 8, 9, 10 (navy blue, medium blue, light blue) instrument spectral response functions against wavelength in microns (top $x$ axis) and wavenumber in $\mathrm{cm}^{-1}$ (bottom $x$ axis).

\subsubsection{Atmospheric inputs: the TIGR dataset}

The simulations have been conducted for the 2311 atmospheres of the TIGR climatological library (Chédin et al., 1985; Chevallier et al., 1998). The 2311 atmospheres are sorted into five air mass types according to their virtual temperature profiles (Achard, 1991; Chédin et al., 1994), which are namely (1) tropical, (2) mid-lat1 for temperate conditions, (3) mid-lat2 for cold temperate and summer polar conditions, (4) polar1 for very cold polar conditions, and (5) polar2 for winter polar conditions. The tropical air mass type is composed of 872 atmospheres, mid-lat1 and mid-lat2 are composed of 388 and 354 atmospheres, respectively, and polar1 and polar2 are composed of 104 and 593 atmospheres, respectively.

\subsubsection{Brightness temperatures simulations}

The 4A model and the TIGR atmospheres input data have been used to simulate the brightness temperatures of IIR and of the candidate companion channels. Each of the five TIGR air mass types includes one individual simulation for each individual atmosphere included in the air mass type (i.e., 872 simulations for the tropical type, 388 for mid-lat1, 354 for mid-lat2, 104 for polar1, and 593 for polar2). Each TIGR air mass type is then characterized through the mean BTD between IIR and MODIS or SEVIRI channels and associated standard deviations derived from the individual simulations (hereafter "TIGR_BTD"). The simulations presented here have been obtained using the 2009 version of the 4A/OP model described above, which does not call into question the initial evaluations conducted before the 2006 launch.

The most suitable radiometric pairings of IIR-MODIS channels for our study are IIR1-MODIS29, IIR2-MODIS31, and IIR3-MODIS32. Similarly, the most suitable IIRSEVIRI pairs are IIR1-SEVIRI8.7, IIR2-SEVIRI10.8, and IIR3-SEVIRI12. Simulations were for SEVIRI/Meteosat 8, which was the primary satellite in June 2006, but our channel selection remains unchanged for the more recent instruments. The ISRFs of these nine channels are plotted in Fig. 2. ISRFs of SEVIRI Meteosat 9 and 10 are also shown for visual comparison with Meteosat 8 . Brightness temperatures derived from the modeled radiances are computed using the relevant ISRF. As an indication, shown in Table 2 are the equivalent central wavenumbers and wavelengths that minimize the differences between the true temperature and the temperature derived using the Planck function over a range of temperatures stretching from $200 \mathrm{~K}$ to $310 \mathrm{~K}$. The central wavenumbers are relevant in the case of blackbody radiances expressed in $\mathrm{W} \mathrm{m}^{-2} \mathrm{sr}^{-1} \mathrm{~cm}$, as in the output of the $4 \mathrm{~A}$ model, whereas the central wavelengths are relevant in the case of radiances reported in $\mathrm{W} \mathrm{m}^{-2} \mathrm{sr}^{-1} \mu \mathrm{m}^{-1}$, as in IIR and MODIS satellite observations. It is noted that the equivalent central wavelengths of IIR1, IIR2, and IIR3 are found to be $8.635,10.644$, and $12.096 \mu \mathrm{m}$, respectively.

The TIGR_BTDs between IIR and MODIS companion channels are reported in Table 3 for the five TIGR air mass types. They are given for MODIS viewing angles of 0,12 , and $20^{\circ}$, chosen according to the latitude-dependent, and therefore air mass type-dependent, range of viewing angles discussed in Sect. 3.1 and shown in Fig. 1. The TIGR_BTDs for each pair of companion channels and their variations with the TIGR air mass type encompass the difference in shape and position of the paired ISRFs and the inherent different sensitivity to surface temperature, temperature and water vapor profiles, and other absorbing atmospheric constituents. For the three pairs of channels, the absolute TIGR_BTDs and the standard deviations are overall larger for the tropical air mass type than for the other air mass types, which is related to the high content and high variability of the water vapor in the tropical regions. Except for the tropics, absolute TIGR_BTDs are smaller than $0.2 \mathrm{~K}$ for IIR1-MODIS29 and $0.1 \mathrm{~K}$ for IIR2-MODIS31, with similar standard deviations smaller than $0.1 \mathrm{~K}$. The largest absolute TIGR_BTDs and standard deviations are for the IIR3-MODIS32 pair, with TIGR_BTDs of about $-1 \mathrm{~K}$ and standard deviations up to $0.3 \mathrm{~K}$ for tropical air mass types.

TIGR_BTDs between IIR and SEVIRI/Meteosat 8 companion channels for the TIGR tropical air mass and SEVIRI viewing angles equal to 0 and $12^{\circ}$ are reported in Table 4 . For a $12^{\circ}$ viewing angle, IIR-SEVIRI TIGR_BTDs differ by up to $0.5 \mathrm{~K}$ from the respective IIR-MODIS TIGR_BTDs.

\section{Implementation of the relative and stand-alone approaches}

For both the relative and the stand-alone approaches, observations of IIR and its companion channels are first spatially 
Table 2. Equivalent central wavelengths and wavenumbers.

\begin{tabular}{lrrr}
\hline & $\begin{array}{r}\text { Channel/wavelength/ } \\
\text { wavenumber }\end{array}$ & $\begin{array}{r}\text { Channel/wavelength/ } \\
\text { wavenumber }\end{array}$ & $\begin{array}{r}\text { Channel/wavelength/ } \\
\text { wavenumber }\end{array}$ \\
\hline IIR & $\# 1: 8.635 \mu \mathrm{m}$ & $\# 2: 10.644 \mu \mathrm{m}$ & $\# 3: 12.096 \mu \mathrm{m}$ \\
& $1158.4 \mathrm{~cm}^{-1}$ & $939.9 \mathrm{~cm}^{-1}$ & $829.1 \mathrm{~cm}^{-1}$ \\
\hline MODIS & $\# 29: 8.553 \mu \mathrm{m}$ & $\# 31: 11.025 \mu \mathrm{m}$ & $\# 32: 12.044 \mu \mathrm{m}$ \\
Aqua & $1169.3 \mathrm{~cm}^{-1}$ & $907.6 \mathrm{~cm}^{-1}$ & $830.8 \mathrm{~cm}^{-1}$ \\
\hline SEVIRI & $\mathrm{IR}^{-1}$ & $\mathrm{IR}^{-1}$ & $\mathrm{IR}^{-1}$ \\
Meteosat 8 & $1148.7 \mathrm{~cm}^{-1}$ & $929.3 \mathrm{~cm}^{-1}$ & $838.7 \mathrm{~cm}^{-1}$ \\
Meteosat 9 & $1148.2 \mathrm{~cm}^{-1}$ & $930.1 \mathrm{~cm}^{-1}$ & $835.8 \mathrm{~cm}^{-1}$ \\
Meteosat 10 & $1147.7 \mathrm{~cm}^{-1}$ & $928.7 \mathrm{~cm}^{-1}$ & $838.0 \mathrm{~cm}^{-1}$ \\
\hline
\end{tabular}

Table 3. Simulated brightness temperature difference (TIGR_BTD) in Kelvin between IIR and MODIS/Aqua companion channels for MODIS viewing angles of 0,12 , and $20^{\circ}$, whenever relevant (NA if not), and standard deviation (in italic) for five air mass types from the TIGR data base.

\begin{tabular}{ll|rrr}
\hline Air mass & $\begin{array}{l}\text { TIGR } \\
\text { Number of Atm. }\end{array}$ & $\begin{array}{r}\text { IIR1-MODIS29 } \\
0^{\circ} / 12^{\circ} / 20^{\circ} / \mathrm{SD}\end{array}$ & $\begin{array}{r}\text { IIR2-MODIS31 } \\
0^{\circ} / 12^{\circ} / 20^{\circ} / \mathrm{SD}\end{array}$ & $\begin{array}{r}\text { IIR3-MODIS32 } \\
0^{\circ} / 12^{\circ} / 20^{\circ} / \mathrm{SD}\end{array}$ \\
\hline tropical & 872 & $\mathrm{NA} / 0.23 / 0.37 / 0.13$ & $\mathrm{NA} / 0.27 / 0.37 / 0.33$ & $\mathrm{NA} /-1.02 /-0.89 / 0.28$ \\
mid-lat1 & 388 & $0.05 / 0.09 / 0.17 / 0.07$ & $0.02 / 0.04 / 0.07 / 0.06$ & $-0.54 /-0.52 /-0.49 / 0.29$ \\
mid-lat2 & 354 & $0.04 / 0.08 / 0.14 / 0.06$ & $-0.01 /-0.00 / 0.02 / 0.02$ & $-0.41 /-0.39 /-0.37 / 0.19$ \\
polar1 & 104 & $0.0 /-0.00 / \mathrm{NA} / 0.04$ & $-0.01 /-0.00 / \mathrm{NA} / 0.03$ & $-0.13 /-0.13 / \mathrm{NA} / 0.15$ \\
polar2 & 593 & $-0.01 / 0.03 / \mathrm{NA} / 0.06$ & $0.03 / 0.03 / \mathrm{NA} / 0.03$ & $-0.15 /-0.15 / \mathrm{NA} / 0.15$ \\
\hline
\end{tabular}

and temporally collocated, as described below, followed by the various steps specific to the implementation of each approach.

\subsection{Collocations}

Collocated observations are from the REMAP product that is developed, processed, and available at the AERIS/ICARE data center. REMAP includes MODIS/Aqua and SEVIRI calibrated radiances collocated with the IIR Level $1 \mathrm{~B}$ radiances and remapped onto the IIR $69 \mathrm{~km}$ grid. MODIS calibrated radiances are from MYD021KM Collection 5 (C5) with geolocation from MYD03 C5. SEVIRI geolocated and calibrated radiances are from the Level 1.5 Image product, which reports spectral blackbody radiances until 7 May 2008 and effective blackbody radiances afterwards (EUMETSAT, 2007b). For each IIR pixel, the collocated MODIS or SEVIRI radiance is from the closest pixel, at sea level. So far, no spatial averaging of the IIR or MODIS $1 \mathrm{~km}$ pixels is performed in order to get a better match with SEVIRI pixels. Thus, one $3 \mathrm{~km}$ resolution sub-satellite SEVIRI pixel is collocated with at least nine different IIR pixels, depending on the SEVIRI viewing angle. IIR and MODIS pixels are collocated with the temporally closest SEVIRI image, which is up to $7 \mathrm{~min} 30 \mathrm{~s}$ before or after the companion observation. IIR and MODIS observations are quasi-coincident and are therefore considered always temporally collocated. Overall,
IIR and MODIS observations are well collocated, whereas a naturally occurring GEO-LEO “mismatch" between SEVIRI and IIR observations cannot be ignored spatially, because of the difference in the pixel sizes and the difference in the satellite zenith angles, nor ignored temporally, because the time difference between the observations can be up to several minutes. This spatial mismatch is minimized by comparing IIR and SEVIRI when SEVIRI viewing angles are less than $10^{\circ}$.

\subsection{Relative approach: outputs and statistical analyses}

Outputs of the relative approach are presented here showing daily means of BTDs and standard deviations. They have been generated for each single day since launch, with daytime and nighttime data either combined or separated, for several $10 \mathrm{~K}$ ranges of observed brightness temperatures, from 290-300 down to 200-210 K.

Statistical analyses of BTDs between pairs of channels over ocean are performed for five latitude ranges: in the tropics $\left(30^{\circ} \mathrm{S}-30^{\circ} \mathrm{N}\right)$, and at mid- $\left(30-60^{\circ}\right)$ and polar $(60$ $82^{\circ}$ ) latitudes in both hemispheres. Oceanic scenes are identified using an index available from the Global Land Onekilometer Base Elevation (GLOBE) project (GLOBE Task Team and others, 1999). Thresholds are defined, which are based on the simulated TIGR_BTDs and associated standard deviations (see Tables 3 and 4) and on the expected instrumental NedT (see Table 1). A "worst case" 
Table 4. Simulated brightness temperature difference (TIGR_BTD) in Kelvin between IIR and SEVIRI/Meteosat 8 companion channels for SEVIRI viewing angles of 0 and $12^{\circ}$, and standard deviation (in italic) for the tropical air mass type from the TIGR data base.

\begin{tabular}{lrrr}
\hline TIGR & IIR1-SEVIRI8.7 & IIR2-SEVIRI10.8 & IIR3-SEVIRI12 \\
Air mass & $0^{\circ} / 12^{\circ} / \mathrm{SD}$ & $0 \% 12^{\circ} / \mathrm{SD}$ & $0 \% 12^{\circ} / \mathrm{SD}$ \\
\hline Tropical & $-0.35 /-0.28 / 0.21$ & $0.06 / 0.12 / 0.1$ & $-0.77 /-0.70 / 0.25$ \\
\hline
\end{tabular}

standard deviation $\sigma$ has been computed by taking $0.4 \mathrm{~K}$ for TIGR_BTD, the IIR NedT specified before launch $(0.5 \mathrm{~K})$, and NedT $=0.1 \mathrm{~K}$ for MODIS and SEVIRI, yielding $\sigma=0.7 \mathrm{~K}$. Using TIGR_BTDs corresponding to each latitude band, BTDs larger or smaller than TIGR_BTD $\pm 3 \sigma$ (i.e., $\pm 2.1 \mathrm{~K}$ ) are considered unrealistic values due to the fact that the instruments presumably do not see the same scenes. The statistics are computed after rejecting these unrealistic values. Because the collocations are at sea level, these tests should minimize parallax issues in the case of elevated clouds.

\subsection{Stand-alone approach}

\subsubsection{Clear sky mask}

After collocation of IIR, MODIS, and SEVIRI companion channels (Sect. 4.1), a clear sky mask is applied to select the relevant pixels for direct comparisons between observations and simulations. The mask is from the Version 3 IIR Level 2 swath product (Vaughan et al., 2015). It is derived from collocated IIR and CALIOP observations along the lidar track and extended to the $69 \mathrm{~km}$ IIR swath by using radiative homogeneity criteria (Garnier et al., 2012). In the Version 3 IIR Level 2 operational algorithm, clear sky track pixels are defined as those pixels for which no cloud layers could be detected by CALIOP and no depolarizing aerosol layers could be detected after averaging the lidar signal up to $20 \mathrm{~km}$ along the track. This information is extracted from the CALIOP Level $25 \mathrm{~km}$ cloud and aerosol layer products (Vaughan et al., 2015). Initial analyses determined that the Version 3 mask is contaminated by the presence of low cloud layers detected by CALIOP at the finest $1 / 3 \mathrm{~km}$ resolution, but not reported in the $5 \mathrm{~km}$ layer product, so they are ignored by the IIR algorithm. This issue will be corrected in the next version (4) of the IIR operational algorithm. Because the new operational product is not available at this time, a corrected mask has been produced specifically for this study. We chose to process each occurrence of January and July from mid-June 2006 to December 2015 to cover the same 9.5-year time period as used in the relative approach for two opposite seasons.

\subsubsection{Clear sky brightness temperatures simulations}

Clear sky simulations of the collocated observations (Sect. 4.1) are carried out using the 4A/OP model (see Sect. 3.2.1) and the temporally and spatially closest atmo- spheric profiles and ocean skin temperatures given by ERAInterim (ERA-I) reanalyses generated at the European Centre for Medium-Range Weather Forecast (ECMWF). We have chosen to use outputs from reanalyses over outputs based on radiosondes measurements (e.g., the LMD Analyzed RadioSoundings Archive, ARSA, database) because of the low density of the radiosonde network over sea. ERA-I reanalyses are available every $6 \mathrm{~h}$ with a nominal resolution of $0.75^{\circ}$ in latitude and longitude. The 4A/OP-simulated radiances are computed for each clear pixel found at a distance smaller than $5 \mathrm{~km}$ from the closest ERA-I input to ensure the highest possible coherence for the comparisons with the observations. This $5 \mathrm{~km}$ threshold was chosen by taking into account the specificity of each of the three instruments (IIR, MODIS, and SEVIRI). The reanalyses outputs give a 61-level description of the temperature, water vapor, and ozone profiles as well as the skin temperature. A comprehensive documentation of the current ERA-I reanalysis system used in this study may be found in Dee et al. (2011). For other absorbers with a constant pressure-dependent mixing ratio $\left(\mathrm{CO}_{2}, \mathrm{~N}_{2} \mathrm{O}\right.$, $\mathrm{CO}, \mathrm{HNO}_{3}, \mathrm{SO}_{2}, \mathrm{CFCs}$, etc.), the most plausible mixing ratio value is used.

The MODIS and SEVIRI viewing angles are outputs of the collocation step (Sect. 4.1), and the IIR is considered a nadir viewing instrument.

Another essential variable for the simulation of the brightness temperatures of these nine window channels is the ocean surface emissivity. As shown for a long time, in many publications, the emissivity depends on wind speed, polarization, temperature, emission angle, and wavenumber (Masuda et al., 1988; Wu and Smith, 1996; Brown and Minnett, 1999; Hanafin and Minnett, 2005; Niclòs et al., 2007). In the present study, variations with wind speed or polarization are not taken into account. Indeed, we chose to favor the consistency with the prelaunch simulations so ocean surface emissivity has been set to 0.98 for all the channels. Again, because MODIS viewing angles are always smaller than $20^{\circ}$ and SEVIRI-selected angles are intentionally limited to $10^{\circ}$, the emissivity dependence on satellite viewing angles is neglected. It is worth pointing out that problems requiring the highest possible absolute accuracy, such as the retrieval of geophysical variables or the validation of radiative transfer models, could not be approached with such approximations. Here, we are more interested in comparing the behavior of the companion channels for each pair of channels than in comparing the pairs. Because each companion channel of 
each pair is processed under the same conditions, using this constant value of the emissivity, there would be a negligible effect on their relative behavior. However, in the planned future reprocessing of the data, and since no limitation comes from the 4A/OP model itself, the required dependencies will be taken into account, in detail, whenever the information is available.

\subsubsection{Outputs and statistical analyses}

The stand-alone approach generates, for each channel, differences between the 4A simulation and the clear sky observation, hereafter called "residuals". For this study, the 4A simulations have been processed for 10 days of each of the chosen months. Outputs are "monthly" mean residuals and associated standard deviations, with daytime and nighttime data either combined or separated. Statistics are built monthly instead of daily, as done in the relative approach, because the number of samples is smaller due to the severe collocation constraints described above. Final statistics are given after removing individual residuals found outside the initial monthly mean \pm twice the initial standard deviation. This procedure is done to prevent undetected cloudy pixels to enter the statistics as well as for situations for which the instruments presumably do not see the same scenes.

\section{Results and findings from the relative approach}

Results from the relative approach are presented hereafter in terms of time series of daily averaged (day and night combined) IIR-MODIS and IIR-SEVIRI BTDs between midJune 2006 and the end of December 2015. The findings derived from the analysis of the various figures are then discussed.

\subsection{Results}

Time series of IIR-MODIS BTD are shown in Figs. 3 to 7 for the five latitude bands, namely $30^{\circ} \mathrm{S}-30^{\circ} \mathrm{N}$ (Fig. 3), 60$30^{\circ} \mathrm{S}$ (Fig. 4), 30-60 $\mathrm{N}$ (Fig. 5), 82-60 $\mathrm{S}$ (Fig. 6), and 60$82^{\circ} \mathrm{N}$ (Fig. 7). Each of these figures includes several panels corresponding to $10 \mathrm{~K}$ brightness temperature domains (decreasing from top to bottom) typically found in their respective latitude bands, and each panel shows the BTD for the three pairs of channels: IIR1-MODIS29 (red), IIR2MODIS31 (green), and IIR3-MODIS32 (blue). The mean number of pixels per day used to build the statistics and the mean standard deviations for each pair of channels are shown at the top of each panel and also in Table 5 for more clarity. The mean number of daily pixels is always larger than $5 \times 10^{3}$ and up to $3.7 \times 10^{6}$ in the tropics at $290-300 \mathrm{~K}$. For each latitude band, the smallest standard deviations are found at the warmest temperatures, with standard deviations ranging from 0.44 to $0.66 \mathrm{~K}$. Standard deviations increase up to $1.1 \mathrm{~K}$ in the tropics at the coldest temperatures, generally as- sociated with increased instrument noise, but perhaps also due in part to larger inhomogeneity of cloudy scenes and to parallax effects at larger MODIS viewing angles. The large daily variability seen at mid- and high latitudes at the coldest temperatures is also attributed to the smaller number of samples (see Table 5). Overall, the results show very stable IIRMODIS BTD since the CALIPSO launch, with some seasonal variations noted, but with a remarkable year-by-year repeatability. These features will be discussed in more detail in Sect. 5.2. It is confirmed that the switch from 0.3 to $3^{\circ}$ of the CALIPSO platform pitch angle at the end of November 2007 (see Sect. 2) has no significant impact, because no discontinuity in the time series can be evidenced.

Time series of IIR-SEVIRI BTD are shown in Fig. 8 for comparison with the IIR-MODIS time series. As explained in Sect. 3.1, only SEVIRI viewing angles smaller than $10^{\circ}$ are chosen. Consequently, the comparisons are only between about $10^{\circ} \mathrm{W}$ and $10^{\circ} \mathrm{E}$ in longitude and between $10^{\circ} \mathrm{S}$ and $10^{\circ} \mathrm{N}$ in latitude. The temperature range is $290-300 \mathrm{~K}$. The mean number of samples per day $\left(5 \times 10^{4}\right)$ is about 100 times smaller than for the IIR-MODIS comparisons. Moreover, the day-to-day variability is more important and the standard deviations are slightly larger (between 0.49 and $0.65 \mathrm{~K})$. The black and grey arrows point to discontinuities in the time series. The discontinuity of up to $0.4 \mathrm{~K}$ in May 2008 (black arrows) is explained by the change of definition in the SEVIRI 1.5 image product from spectral to effective blackbody radiances on 7 May 2008. For simplicity, this change is not accounted for in this analysis, which assumes effective blackbody radiances. This discontinuity was already evidenced in the initial analyses reported in Scott (2009). In addition, discontinuities of smaller amplitude (grey arrows) are seen in April 2007, which correspond to the switch from Meteosat 8 to Meteosat 9, and in January 2013, which coincide with the switch to Meteosat 10 . These small discontinuities are explained by the fact that the SEVIRI brightness temperatures are computed using the Meteosat 8 ISRFs for the entire period. The discontinuities in the time series illustrate the sensitivity of the technique to detect instrumental changes.

\subsection{Findings}

As seen in Sect. 5.1, considering the fact that the IIR and MODIS/Aqua both fly in the A-Train, and considering no instrumental changes since CALIPSO launched, monitoring differences between IIR and MODIS/Aqua observations turns out to be a more fruitful approach for the assessment of the IIR calibration stability than monitoring differences between IIR and SEVIRI. Thus, the findings discussed in the following sections are based mostly on the IIR-MODIS comparisons shown in Figs. 3 to 7. In this section, we discuss first the consistency of the IIR-MODIS and IIR-SEVIRI BTD at warm temperatures with our prelaunch evaluation from the five TIGR air mass types. Then, we successively discuss 
Table 5. Mean number of pixels per day (bold) and mean standard deviations in Kelvin (from left to right: $x=$ IIR1-MODIS29, $y=$ IIR2MODIS31, and $z=$ IIR3-MODIS32) associated with Figs. 3 to 7.

\begin{tabular}{|c|c|c|c|c|c|}
\hline & $\begin{array}{r}30^{\circ} \mathrm{S}-30^{\circ} \mathrm{N} \\
\text { (Fig. 3) } \\
\text { Pixels } \\
x / y / z\end{array}$ & $\begin{array}{r}60-30^{\circ} \mathrm{S} \\
\text { (Fig. 4) } \\
\text { Pixels } \\
x / y / z\end{array}$ & $\begin{array}{r}30-60^{\circ} \mathrm{N} \\
\text { (Fig. 5) } \\
\text { Pixels } \\
x / y / z\end{array}$ & $\begin{array}{r}82-60^{\circ} \mathrm{S} \\
\text { (Fig. 6) } \\
\text { Pixels } \\
x / y / z\end{array}$ & $\begin{array}{r}60-82^{\circ} \mathrm{N} \\
\text { (Fig. 7) } \\
\text { Pixels } \\
x / y / z\end{array}$ \\
\hline $290-300 \mathrm{~K}$ & $\begin{array}{r}\mathbf{3 . 7} \times \mathbf{1 0}^{\mathbf{6}} \\
0.48 / 0.63 / 0.48\end{array}$ & - & - & - & - \\
\hline $280-290 \mathrm{~K}$ & $\begin{array}{r}\mathbf{2 . 1} \times \mathbf{1 0}^{\mathbf{6}} \\
0.83 / 0.88 / 0.84\end{array}$ & $\begin{array}{r}\mathbf{1} \times \mathbf{1 0}^{\mathbf{6}} \\
0.56 / 0.66 / 0.63\end{array}$ & $\begin{array}{r}\mathbf{6 . 8} \times \mathbf{1 0}^{\mathbf{5}} \\
0.57 / 0.66 / 0.64\end{array}$ & - & - \\
\hline $270-280 \mathrm{~K}$ & $\begin{array}{r}\mathbf{5 . 4} \times \mathbf{1 0}^{\mathbf{5}} \\
0.87 / 0.95 / 0.94\end{array}$ & $\begin{array}{r}1.5 \times \mathbf{1 0}^{\mathbf{6}} \\
0.68 / 0.73 / 0.71\end{array}$ & $\begin{array}{r}\mathbf{6 . 8} \times \mathbf{1 0}^{\mathbf{5}} \\
0.69 / 0.77 / 0.74\end{array}$ & $\begin{array}{r}\mathbf{5 . 9} \times \mathbf{1 0}^{\mathbf{4}} \\
0.44 / 0.52 / 0.5\end{array}$ & $\begin{array}{r}\mathbf{4 . 1} \times \mathbf{1 0}^{\mathbf{5}} \\
0.55 / 0.62 / 0.61\end{array}$ \\
\hline $260-270 \mathrm{~K}$ & $\begin{array}{c}\mathbf{1 . 7} \times \mathbf{1 0}^{\mathbf{5}} \\
1.1 / 1.1 / 1.1\end{array}$ & $\begin{array}{r}1.1 \times \mathbf{1 0}^{\mathbf{6}} \\
0.77 / 0.82 / 0.79\end{array}$ & $\begin{array}{r}\mathbf{4 . 3} \times \mathbf{1 0}^{\mathbf{5}} \\
0.84 / 0.89 / 0.87\end{array}$ & $\begin{array}{r}\mathbf{6 . 0} \times \mathbf{1 0}^{\mathbf{5}} \\
0.61 / 0.68 / 0.64\end{array}$ & $\begin{array}{r}\mathbf{8 . 4} \times \mathbf{1 0}^{\mathbf{5}} \\
0.66 / 0.72 / 0.70\end{array}$ \\
\hline $250-260 \mathrm{~K}$ & $\begin{array}{r}\mathbf{1 . 1} \times \mathbf{1 0}^{\mathbf{5}} \\
1.1 / 1.1 / 1.1\end{array}$ & $\begin{array}{r}\mathbf{6 . 9} \times \mathbf{1 0}^{\mathbf{5}} \\
0.82 / 0.87 / 0.85\end{array}$ & $\begin{array}{r}\mathbf{2 . 7} \times \mathbf{1 0}^{\mathbf{5}} \\
0.90 / 0.94 / 0.93\end{array}$ & $\begin{array}{r}\mathbf{1 . 0} \times \mathbf{1 0}^{\mathbf{6}} \\
0.61 / 0.67 / 0.63\end{array}$ & $\begin{array}{r}\mathbf{9 . 1} \times \mathbf{1 0}^{\mathbf{5}} \\
0.68 / 0.71 / 0.70\end{array}$ \\
\hline $240-250 \mathrm{~K}$ & $\begin{array}{r}\mathbf{7 . 9} \times \mathbf{1 0}^{\mathbf{4}} \\
1.1 / 1.1 / 1.2\end{array}$ & $\begin{array}{r}\mathbf{3 . 8} \times \mathbf{1 0}^{\mathbf{5}} \\
0.89 / 0.90 / 0.90\end{array}$ & $\begin{array}{r}\mathbf{1 . 4} \times \mathbf{1 0}^{\mathbf{5}} \\
0.97 / 0.98 / 0.98\end{array}$ & $\begin{array}{r}\mathbf{8 . 1} \times \mathbf{1 0}^{\mathbf{5}} \\
0.62 / 0.69 / 0.65\end{array}$ & $\begin{array}{r}\mathbf{6 . 6} \times \mathbf{1 0}^{\mathbf{5}} \\
0.72 / 0.75 / 0.75\end{array}$ \\
\hline $230-240 \mathrm{~K}$ & $\begin{array}{r}\mathbf{6 . 6} \times \mathbf{1 0}^{\mathbf{4}} \\
1.1 / 1.1 / 1.2\end{array}$ & $\begin{array}{r}\mathbf{1 . 8} \times \mathbf{1 0}^{\mathbf{5}} \\
0.91 / 0.92 / 0.93\end{array}$ & $\begin{array}{r}\mathbf{7 . 8} \times \mathbf{1 0}^{\mathbf{4}} \\
0.97 / 0.98 / 0.98\end{array}$ & $\begin{array}{r}\mathbf{2 . 6} \times \mathbf{1 0}^{\mathbf{5}} \\
0.65 / 0.72 / 0.71\end{array}$ & $\begin{array}{r}\mathbf{1 . 7} \times \mathbf{1 0}^{\mathbf{5}} \\
0.80 / 0.81 / 0.81\end{array}$ \\
\hline $220-230 \mathrm{~K}$ & $\begin{array}{r}\mathbf{5 . 7} \times \mathbf{1 0}^{\mathbf{4}} \\
1.1 / 1.1 / 1.1\end{array}$ & $\begin{array}{r}\mathbf{5 . 8} \times \mathbf{1 0}^{\mathbf{4}} \\
0.94 / 0.94 / 0.94\end{array}$ & $\begin{array}{r}\mathbf{2 . 9} \times \mathbf{1 0}^{\mathbf{4}} \\
0.99 / 0.99 / 0.99\end{array}$ & $\begin{array}{r}\mathbf{9 . 8} \times \mathbf{1 0}^{\mathbf{4}} \\
0.67 / 0.71 / 0.71\end{array}$ & $\begin{array}{r}\mathbf{1 . 3} \times \mathbf{1 0}^{\mathbf{4}} \\
0.87 / 0.87 / 0.86\end{array}$ \\
\hline $210-220 \mathrm{~K}$ & $\begin{array}{r}\mathbf{3 . 9} \times \mathbf{1 0}^{\mathbf{4}} \\
1.1 / 1.1 / 1.1\end{array}$ & $\begin{array}{r}\mathbf{7 . 6} \times \mathbf{1 0}^{\mathbf{3}} \\
0.98 / 0.96 / 0.95\end{array}$ & $\begin{array}{r}\mathbf{5 . 1 x} \times \mathbf{1 0}^{\mathbf{3}} \\
0.99 / 0.97 / 0.97\end{array}$ & - & - \\
\hline $200-210 \mathrm{~K}$ & $\begin{array}{c}\mathbf{1 . 7} \times \mathbf{1 0}^{\mathbf{4}} \\
1.1 / 1.1 / 1.1\end{array}$ & - & - & - & - \\
\hline
\end{tabular}

Table 6. IIR-MODIS brightness temperature differences in Kelvin at the beginning of the CALIPSO mission and associated uncertainty at the warmest temperature range in each latitude band.

\begin{tabular}{lrrr}
\hline Latitudes and temperatures & IIR1-MODIS29 & IIR2-MODIS31 & IIR3-MODIS32 \\
\hline $30^{\circ} \mathrm{S}-30^{\circ} \mathrm{N}, 290-300 \mathrm{~K}$ & $0.336 \pm 0.001$ & $0.511 \pm 0.002$ & $-0.736 \pm 0.001$ \\
$60-30^{\circ} \mathrm{S}, 280-290 \mathrm{~K}$ & $0.176 \pm 0.001$ & $0.228 \pm 0.001$ & $-0.469 \pm 0.001$ \\
$30-60^{\circ} \mathrm{N}, 280-290 \mathrm{~K}$ & $0.170 \pm 0.002$ & $0.304 \pm 0.003$ & $-0.445 \pm 0.003$ \\
$82-60^{\circ} \mathrm{S}, 270-280 \mathrm{~K}$ & $0.121 \pm 0.002$ & $0.255 \pm 0.002$ & $-0.113 \pm 0.002$ \\
$60-82^{\circ} \mathrm{N}, 270-280 \mathrm{~K}$ & $0.159 \pm 0.003$ & $0.484 \pm 0.004$ & $0.055 \pm 0.003$ \\
\hline
\end{tabular}

the IIR-MODIS results at cold temperatures, the long-term trends, and the seasonal variations.

\subsubsection{Warm scenes}

The first step of the analysis is to compare the mean BTD from the relative approach with the simulated TIGR_BTDs (see Sect. 3.2.3). Because the TIGR simulations are for clear sky conditions, the comparisons are conducted for the warmest temperature range at each latitude band. Indeed, the clear sky scenes are a priori the warmest ones, although the warmest scenes could also contain clouds of weak absorption or thicker clouds located near the surface. After application of the (TIGR_BTD $\pm 2.1 \mathrm{~K}$ ) thresholds introduced in Sect. 4.2, more than $95 \%$ of the pixels contribute to the statistics, and the mean BTDs are changed by less than
$0.15 \mathrm{~K}$, confirming that the thresholding method is appropriate. The IIR-MODIS BTDs at the beginning of the mission derived from linear regression lines are reported in Table 6 for comparison against the TIGR_BTDs reported in Table 3. The observed IIR-MODIS BTDs in the tropics at 290-300 K and the TIGR_BTDs for tropical air mass types differ by less than $0.1 \mathrm{~K}$ for IIR1-MODIS29, 0.25 K for IIR2-MODIS31, and $0.3 \mathrm{~K}$ for IIR3-MODIS32. The observed mean BTD at $30-60^{\circ}$ and at $280-290 \mathrm{~K}$ in the Northern and Southern Hemispheres and the TIGR_BTDs at mid-latitude (midlat1 and mid-lat2) also agree within about $0.1 \mathrm{~K}$ for IIR1MODIS29 and IIR3-MODIS32 and are within 0.2 to $0.3 \mathrm{~K}$ for IIR2-MODIS31. The same conclusions apply for the mean BTD at $60-82^{\circ} \mathrm{S}$ and at $270-280 \mathrm{~K}$ when compared with the TIGR_BTDs for polar1 and polar2 atmospheres. At $60-82^{\circ} \mathrm{N}$, IIR2-MODIS31 and IIR3-MODIS32 BTDs 


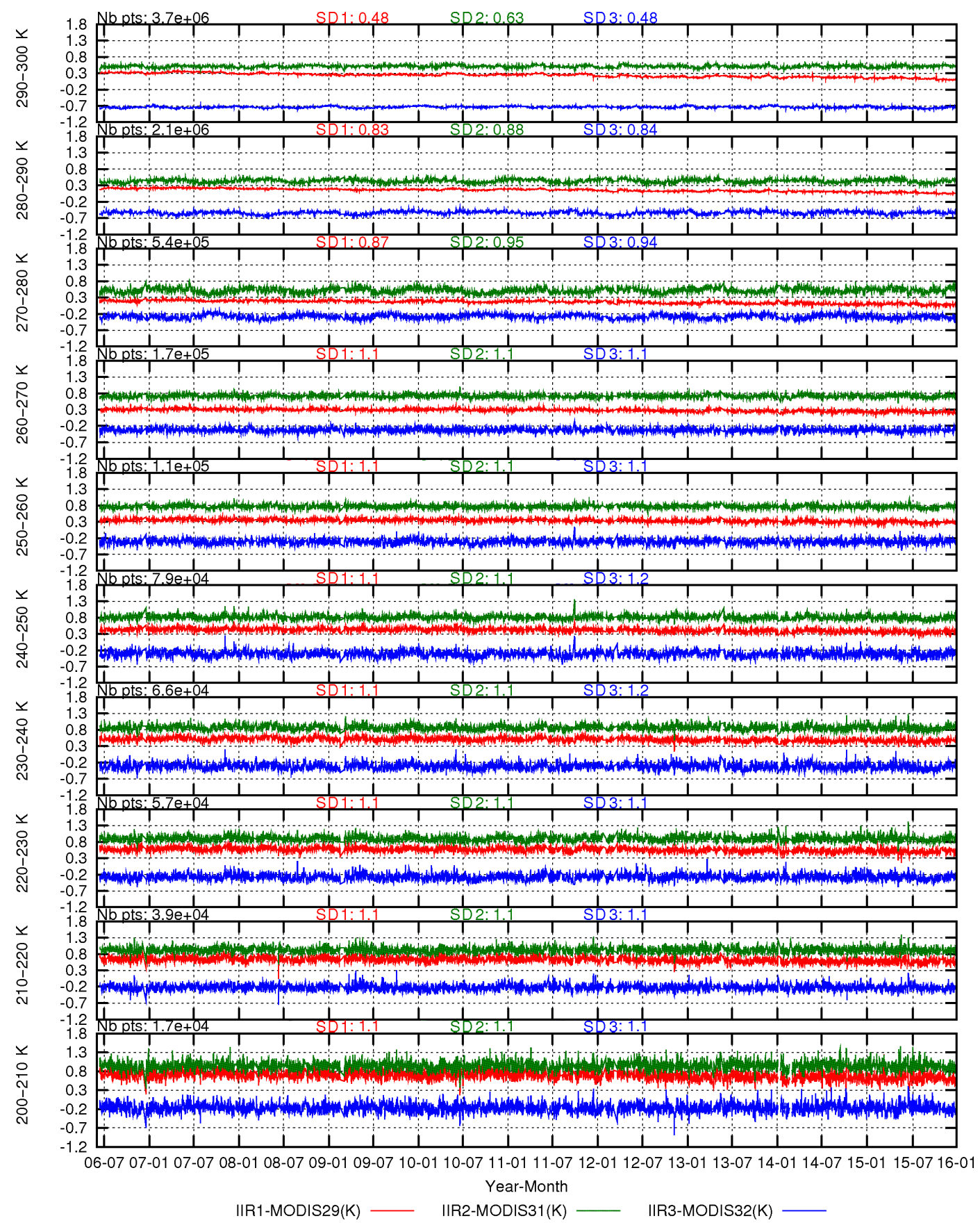

Figure 3. Time series ( $x$ axis: year-month) of daily averaged (day and night combined) IIR-MODIS brightness temperature differences ( $y$-axis units: Kelvin) for the three pairs of companion channels (red: IIR1-MODIS29, green: IIR2-MODIS31, blue: IIR3-MODIS32) over ocean in the tropics at $30^{\circ} \mathrm{S}-30^{\circ} \mathrm{N}$. Each panel is for a given range in brightness temperature from $290-300 \mathrm{~K}$ (top) down to $200-210 \mathrm{~K}$ (bottom). Added at the top of each panel are the mean number of points per day ( $\mathrm{Nb}$ pts) and the mean standard deviation per day for each of the three pairs (see Table 5).

are larger than at $60-82^{\circ} \mathrm{S}$ by about $0.2 \mathrm{~K}$, which degrades the comparisons against the TIGR_BTDs. Overall, these results demonstrate good consistency between observed IIRMODIS BTDs and simulated TIGR_BTDs. Direct comparisons between observations and simulations in clear sky con- ditions will be discussed in Sect. 6 with the stand-alone approach.

Even though the following is based on comparisons with MODIS/Aqua, it is interesting to compare the observed IIRSEVIRI BTDs and the TIGR_BTDs in the tropics (Table 4). 


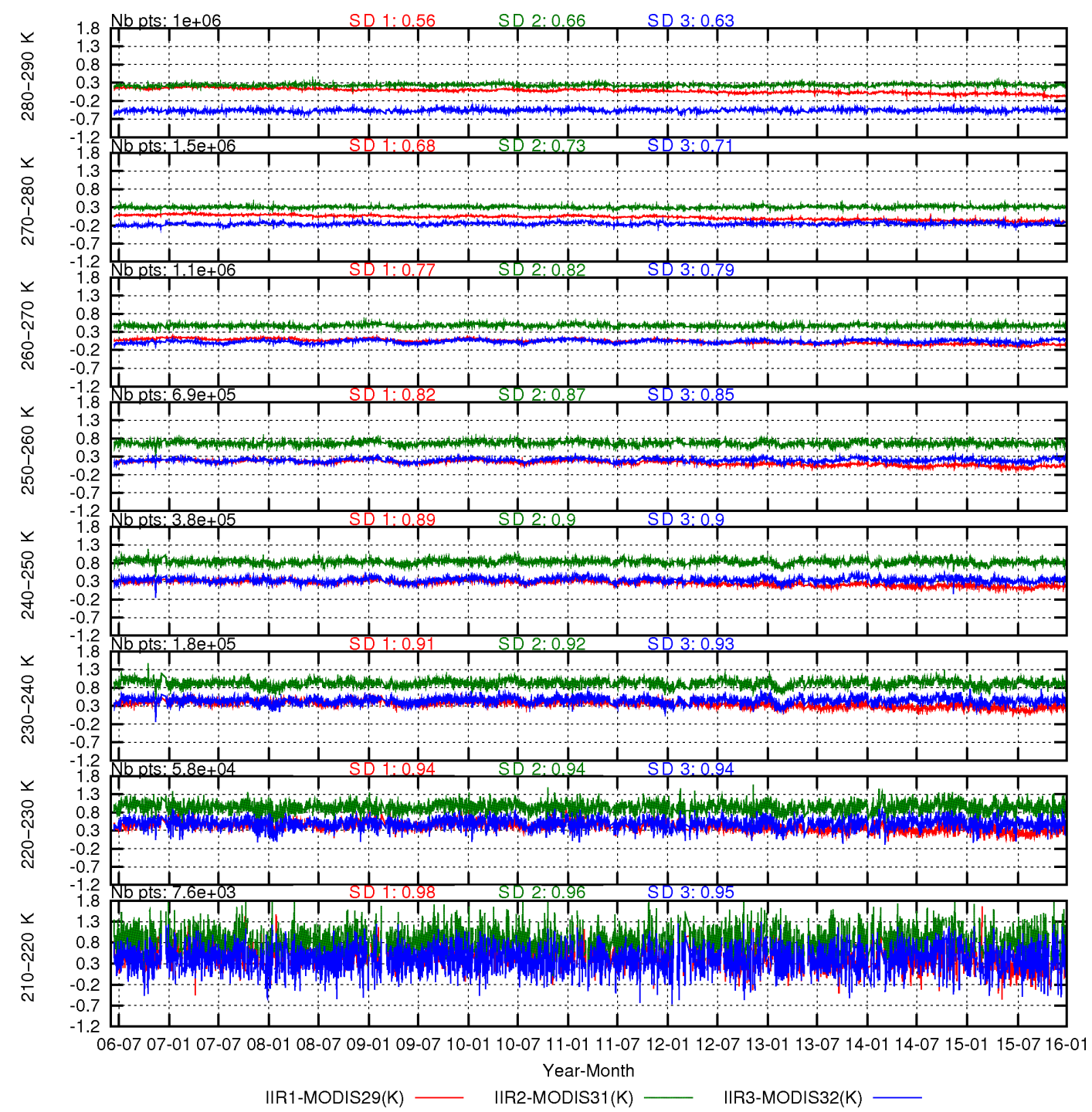

Figure 4. Time series ( $x$ axis: year-month) of daily averaged (day and night combined) IIR-MODIS brightness temperature differences ( $y$-axis units: Kelvin) for the three pairs of companion channels (red: IIR1-MODIS29, green: IIR2-MODIS31, blue: IIR3-MODIS32) over ocean at $60-30^{\circ} \mathrm{S}$. Each panel is for a given range in brightness temperature from 280-290 K (top) down to 210-220 K (bottom). Added at the top of each panel are the mean number of points per day ( $\mathrm{Nb}$ pts) and the mean standard deviation per day for each of the three pairs (see Table 5).

After May 2008, when the radiances reported in the SEVIRI products are effective blackbody radiances, the TIGR_BTDs are in fair agreement with the differences plotted in Fig. 8, keeping in mind that the SEVIRI observations are from Meteosat 9 and 10 after May 2008, whereas the TIGR simulations are for SEVIRI/Meteosat 8.

\subsubsection{Cold scenes}

As the scene temperature decreases, the clouds are denser and colder, and the contribution from such absorbing clouds increases while the influence of the surface and near-surface atmosphere decreases. The fraction of pixels retained after application of the thresholding scheme described in Sect. 4.2 is found to decrease progressively from $95 \%$ for the warm scenes to $30 \%$, with the smallest fraction observed at 200 $210 \mathrm{~K}$ in the tropics for the IIR3-MODIS32 pair. This is partly due to the fact that the BTDs are distributed over a broader range of values than anticipated, so that the mean BTD seen in Figs. 3 to 7 may be significantly, but systematically, biased for the cold scenes. For a better quantification as temperature decreases, IIR-MODIS BTDs are evaluated using the median values of the whole distributions, without thresholding. The median value is preferred to the mean value to minimize the impact of presumably unrealistic values. Median IIR1-MODIS29 (red), IIR2-MODIS31 (green), 


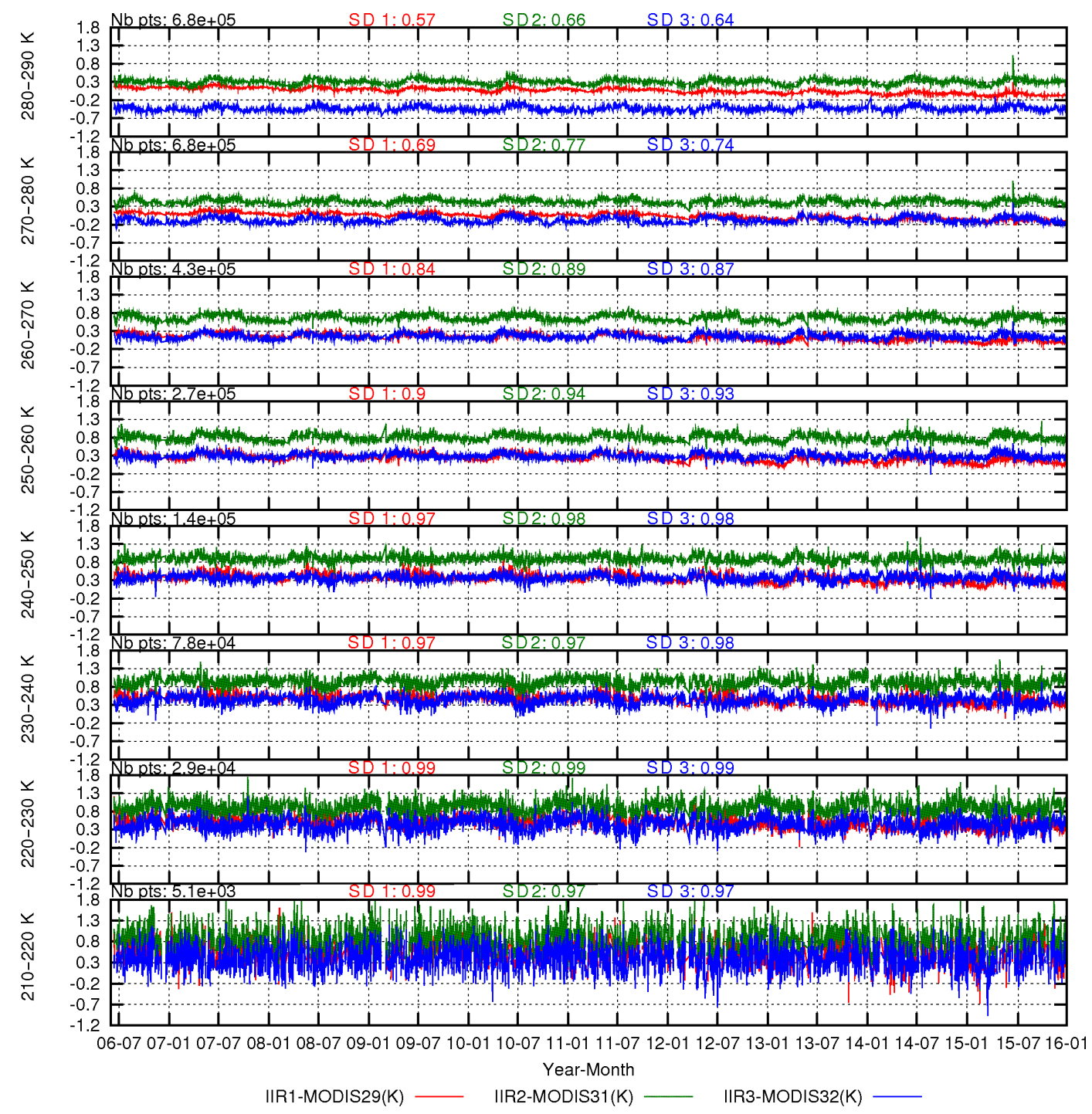

Figure 5. Same as Fig. 4 but at $30-60^{\circ} \mathrm{N}$.

and IIR3-MODIS32 (blue) BTDs are shown in Fig. 9a by temperature ranges from $190-200$ to $280-290 \mathrm{~K}$ in the tropics during 2008 for representative months of the four seasons. Mean absolute deviations from the median value are between 2.5 and $5 \mathrm{~K}$. For further evaluation, IIR and MODIS inter-channel BTDs have been analyzed. Following the same approach as in Fig. 9a, Fig. 9b shows median IIR1-IIR3 (red, solid), IIR2-IIR3 (green, solid), MODIS29-MODIS32 (red, dashed), and MODIS31-MODIS32 (green, dashed) BTDs. Mean absolute deviations from the median value are between 0.5 and $3 \mathrm{~K}$. The variations of both IIR and MODIS inter-channel BTDs with temperature are due to the changing optical and microphysical properties of absorbing ice and water clouds located at various altitudes. The analysis of arches as seen in Fig. 9b is the essence of the wellknown split-window technique for the retrieval of cloud microphysical properties (Inoue, 1985; Ackerman et al., 1990).
IIR and MODIS arches are not of the same amplitude because IIR and MODIS measurements are spectrally different. The BTDs at the coldest temperatures (190-200 K) provide useful information regarding the calibration. Indeed, the coldest temperatures (190-200 K) correspond a priori to elevated dense ice clouds, which, if they behave as blackbody sources, should lead to quasi-identical brightness temperatures for all channels, assuming a negligible contribution from the atmosphere above the cloud. This is what we observe in Fig. 9b, where the IIR and MODIS inter-channel BTDs are close to zero, showing internal consistency of the calibration within each instrument. However, Fig. 9a shows that the IIR-MODIS BTDs are about $1.6 \mathrm{~K}$ on average at 190-200 K for the three pairs of channels. This indicates a warm bias of $1.6 \mathrm{~K}$ of IIR with respect to MODIS at 190 $200 \mathrm{~K}$. According to Fig. 9a, the warm bias seems to increase progressively as temperature decreases. An increasing IIR 


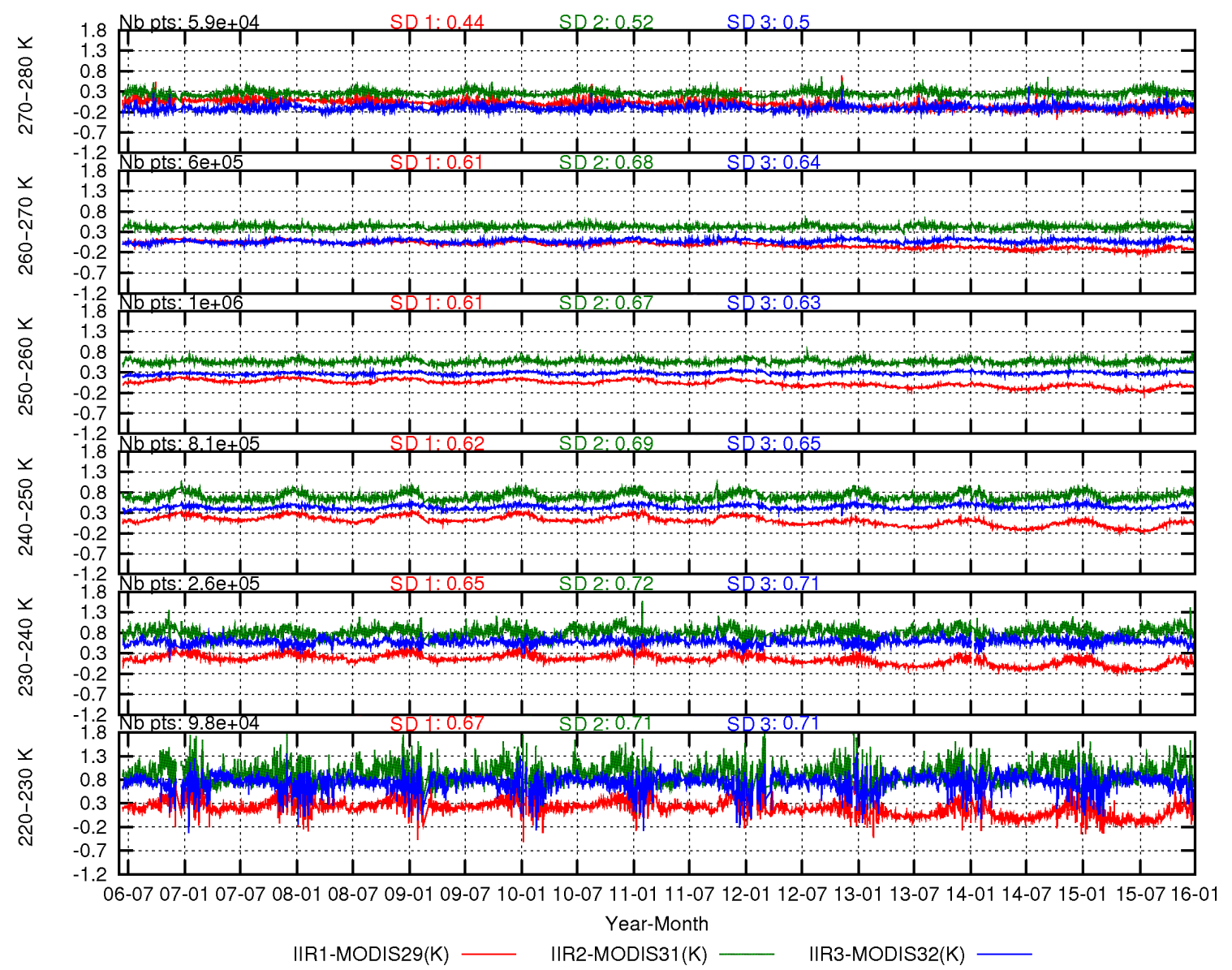

Figure 6. Time series ( $x$ axis: year-month) of daily averaged (day and night combined) IIR-MODIS brightness temperature differences ( $y$-axis units: Kelvin) for the three pairs of companion channels (red: IIR1-MODIS29, green: IIR2-MODIS31, blue: IIR3-MODIS32) over ocean at $82-60^{\circ} \mathrm{S}$. Each panel is for a given range in brightness temperature from 270-280 K (top) down to $220-230 \mathrm{~K}$ (bottom). Added at the top of each panel are the mean number of points per day ( $\mathrm{Nb}$ pts) and the mean standard deviation per day for each of the three pairs (see Table 5).

calibration bias as temperature decreases could be explained by a drift of the gain with respect to the gain measured in flight at warm temperature. Because IIR has only one sensor, observing such a similar bias for all three channels is conceivable.

\subsubsection{Long-term trends}

IIR-MODIS BTDs are very stable year-by-year since midJune 2006. In order to quantify the trends over the first 9.5 years of the CALIPSO mission, linear regression lines have been computed for each of the time series shown in Figs. 3 to 7. The slopes of these lines well approximate the trend of the IIR-MODIS brightness temperature differences since the beginning of the CALIPSO mission. These trends are plotted against temperature in Fig. 10 for each pair of channels and for each of the five latitude bands. An unambiguous trend is seen for IIR1-MODIS29 (red) at any temperature and at any latitude, varying between -0.01 and
$-0.03 \mathrm{~K} \mathrm{yr}^{-1}$. It is $-0.019 \pm 0.0002 \mathrm{~K} \mathrm{yr}^{-1}$ at $290-300 \mathrm{~K}$ in the tropics and $-0.02 \pm 0.0004 \mathrm{~K} \mathrm{yr}^{-1}$ on average. This trend, which represents $-0.19 \mathrm{~K}$ over the 9.5 -year period, can also be seen directly in Figs. 3 to 7. However, the trend of the order of $0.005 \mathrm{~K} \mathrm{yr}^{-1}$ or less in absolute value for IIR2MODIS31 (green) and IIR3-MODIS32 (blue) is deemed not significant. Notwithstanding the small trend evidenced for IIR1-MODIS29, which is further investigated in Sect. 6 using the stand-alone approach, the long-term stability of the IIR instrument with respect to MODIS/Aqua between June 2006 and the end of 2015 is remarkable.

\subsubsection{Seasonal variations}

Seasonal variations of the IIR-MODIS BTD are sometimes observed at mid- and high latitude in Figs. 4 to 7. More specifically, it can be noted by comparing Figs. 4 and 5 on one hand (mid-latitudes) and Figs. 6 and 7 on the other hand (polar latitudes) that at any scene temperature, including the 


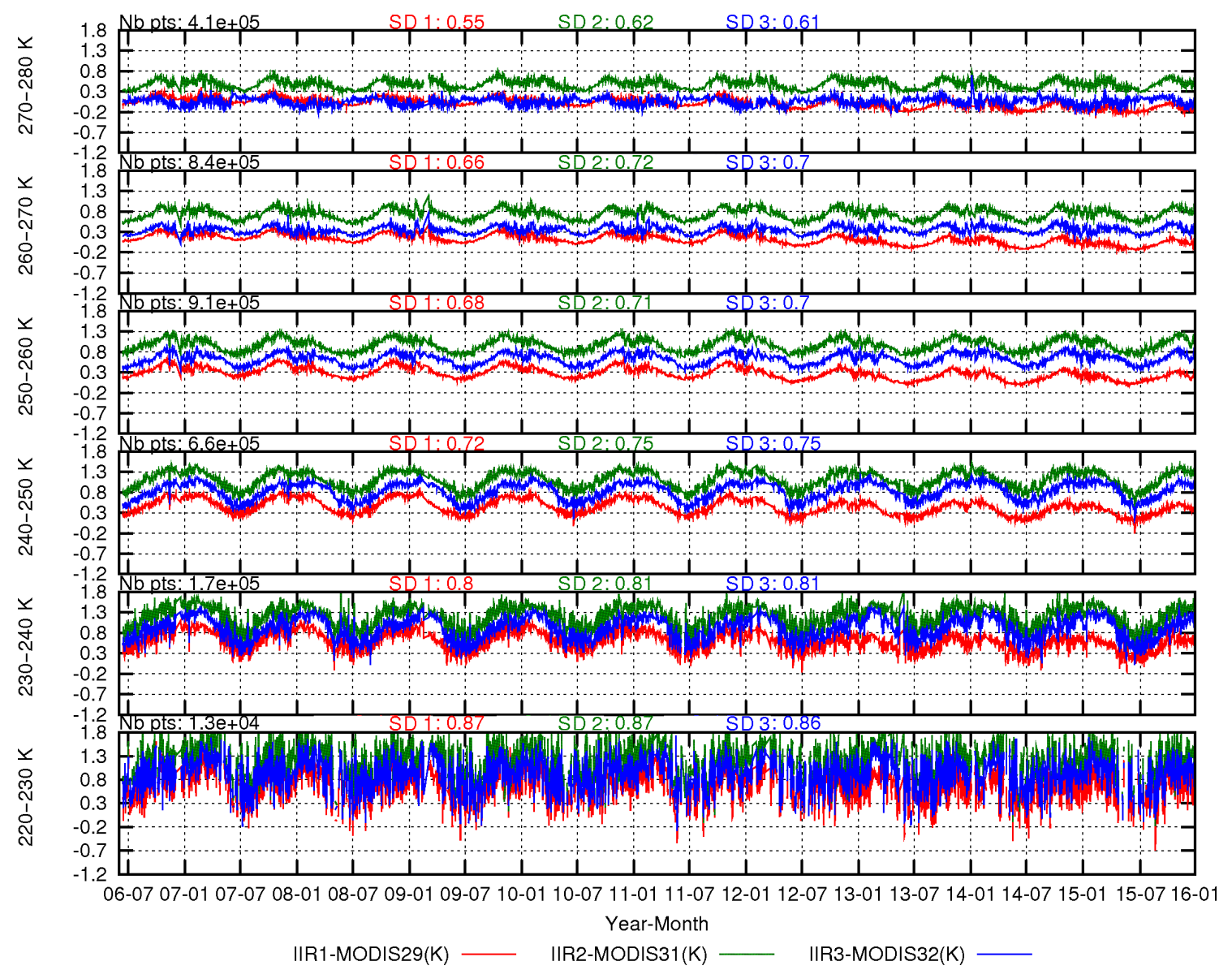

Figure 7. Same as Fig. 6 but at $60-82^{\circ} \mathrm{N}$.

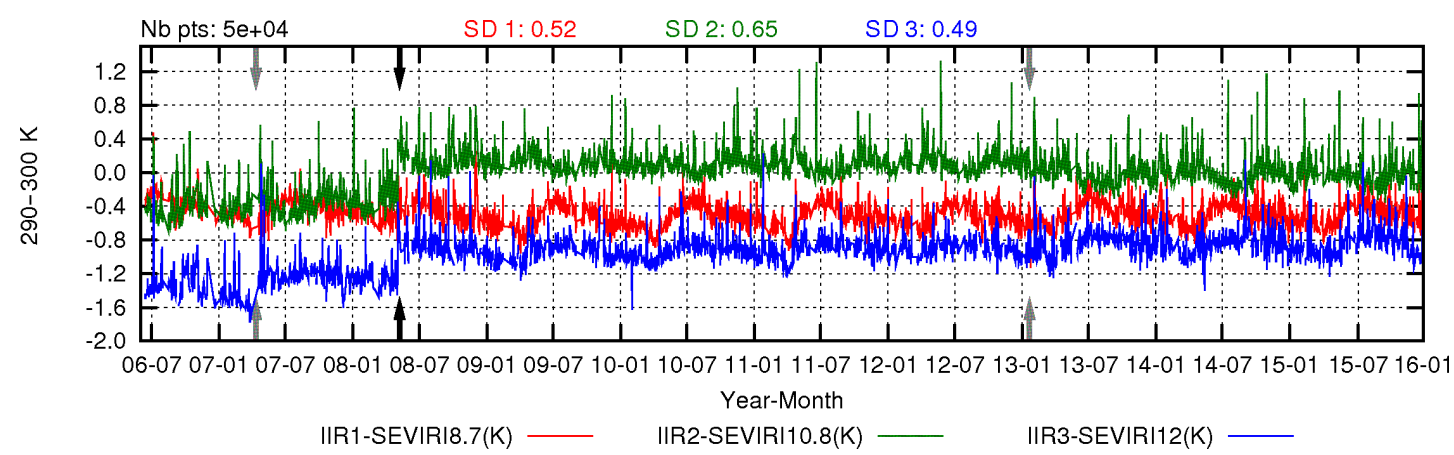

Figure 8. Time series ( $x$ axis: year-month) of IIR-SEVIRI brightness temperature differences ( $y$-axis units: Kelvin) for the three pairs of companion channels (red: IIR1-SEVIRI8.7, green: IIR2-SEVIRI10.8, blue: IIR3-SEVIRI12) over ocean at 290-300 K for SEVIRI viewing angles smaller than $10^{\circ}$. Added at the top of each panel are the mean number of points per day (Nb pts) and the mean standard deviation per day for each of the three pairs. The black arrows indicate the change in the definition of the SEVIRI product in May 2008. The grey arrows indicate the switch from Meteosat 8 to 9 in April 2007 and from Meteosat 9 to 10 in January 2013.

warmest temperatures, with presumably the smallest influence from clouds, a seasonal variability is clearly seen in the Northern Hemisphere but barely in the Southern Hemisphere. It was found that at mid-latitudes, where observations during both daytime and nighttime are available year-round, the larger seasonal variability in the Northern Hemisphere is related to significant differences between nighttime and daytime IIR-MODIS BTDs. This is illustrated in Figs. 11 and 12, where the IIR-MODIS BTDs are shown for each pair of channels at $30-60^{\circ} \mathrm{N}$ (Fig. 11) and at $60-30^{\circ} \mathrm{S}$ (Fig. 12), 

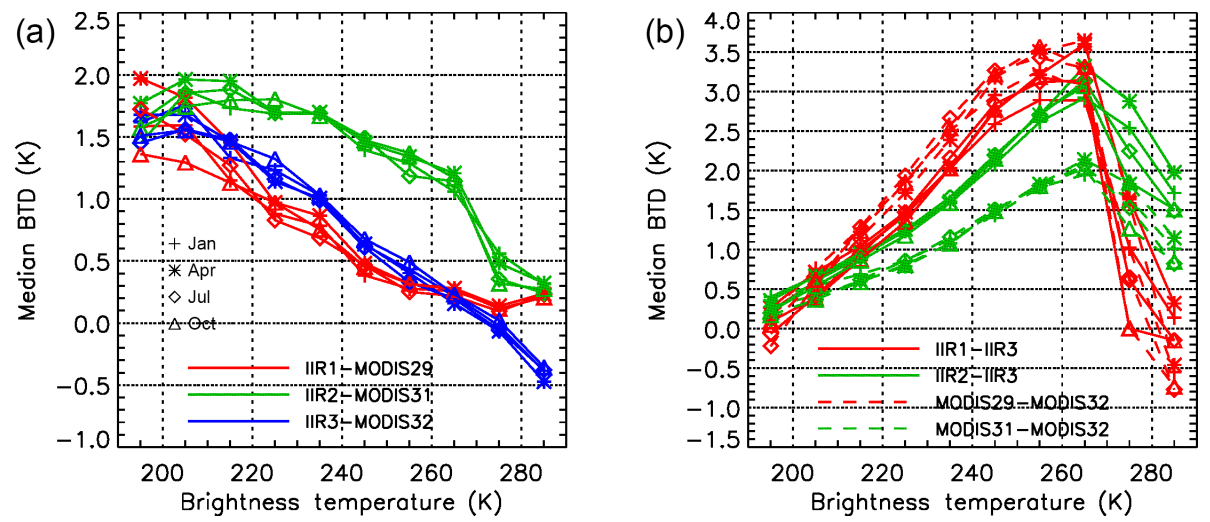

Figure 9. (a) Median IIR1-MODIS29 (red), IIR2-MODIS31 (green), and IIR3-MODIS32 (blue) brightness temperature differences against brightness temperature. (b) Median IIR1-IIR3 (red, solid), IIR2-IIR3 (green, solid), MODIS29-MODIS32 (red, dashed), and MODIS31MODIS32 (green, dashed) brightness temperature differences against temperature. Plus sign: January 2008, star: April 2008, diamond: July 2008, triangle: October 2008. Latitude band: $30^{\circ} \mathrm{S}-30^{\circ} \mathrm{N}$, ocean.
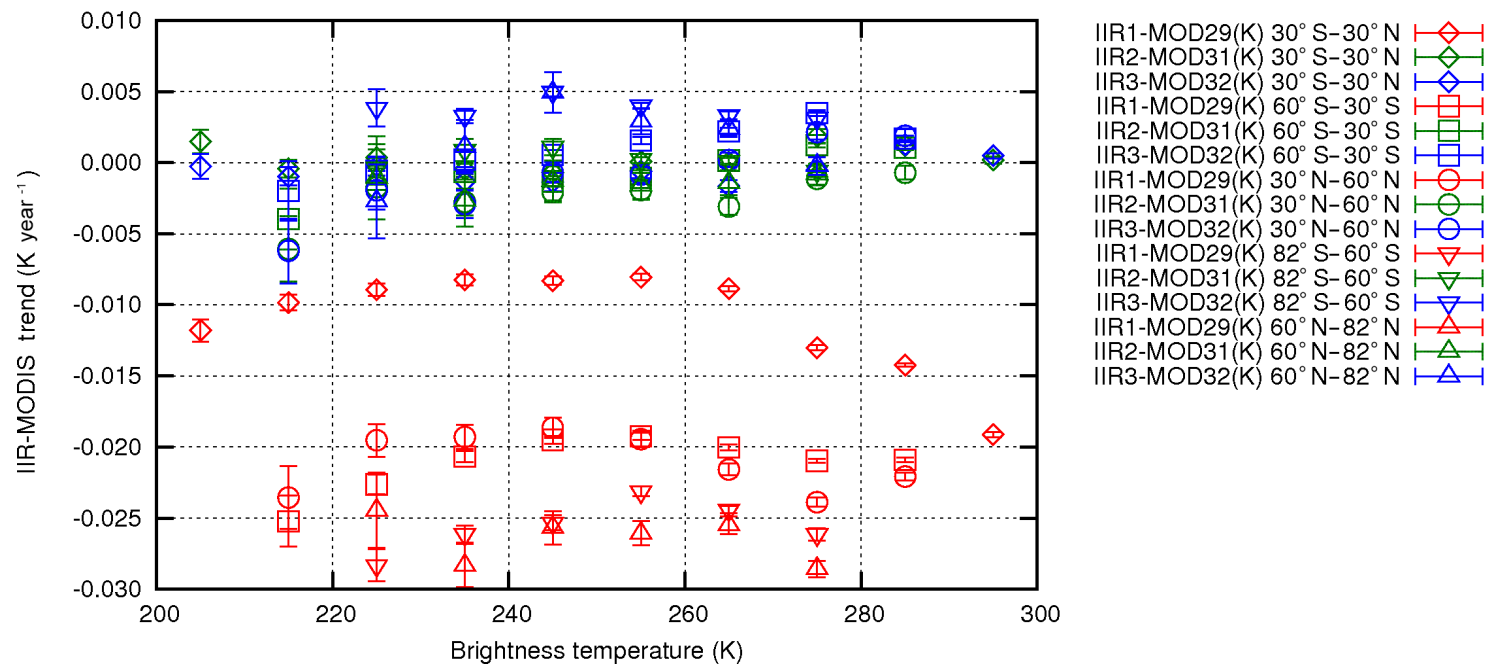

Figure 10. Trends of IIR-MODIS brightness temperature differences and associated uncertainties against temperature for the three pairs of companion channels (red: IIR1-MODIS29, green: IIR2-MODIS31, blue: IIR3-MODIS32) as derived from Figs. 3 to 7. Latitude bands: diamond, $30^{\circ} \mathrm{S}-30^{\circ} \mathrm{N}$; square, $60-30^{\circ} \mathrm{S}$; circle, $30-60^{\circ} \mathrm{N}$; inverse triangle, $82-60^{\circ} \mathrm{S}$; triangle, $60-82^{\circ} \mathrm{N}$.

at $280-290 \mathrm{~K}$, and by distinguishing daytime data (in red) from nighttime data (in blue). The BTDs obtained by combining daytime and nighttime data, as in Figs. 4 and 5, are plotted in black for reference. At $30-60^{\circ} \mathrm{N}$ (Fig. 11), seasonal night/day biases are seen for the three pairs of IIRMODIS channels, whereas no night/day biases are seen in the Southern Hemisphere at $60-30^{\circ} \mathrm{S}$ (Fig. 12). The largest bias at $30-60^{\circ} \mathrm{N}$ is during June and July, with a night-minusday difference equal to $+0.4 \mathrm{~K}$ for IIR2-MODIS31 (middle) and IIR3-MODIS32 (bottom) and equal to about $+0.2 \mathrm{~K}$ for IIR1-MODIS29 (top). In the opposite season, no night/day bias is seen for IIR1-MODIS29, whereas the night-day difference is about $-0.1 \mathrm{~K}$ for the other pairs. This behavior is further discussed in Sect. 6 after the presentation of additional information from the stand-alone approach.

\section{Results and further findings from the stand-alone approach}

The stand-alone approach has been applied to each of the three IIR channels and each of their three MODIS and SEVIRI companion channels to directly compare clear sky simulations and clear sky measurements. Here, results are shown for IIR and MODIS only, for each month of January and July from mid-2006 to the end 2015, with the corrected clear sky mask processed as described in Sect. 4.3.1. From the relative approach (Sect. 5.2.3), a trend of $-0.02 \mathrm{~K} \mathrm{yr}^{-1}$ on average is detected for IIR1-MODIS29, which could originate from one channel or from both. The stand-alone approach allows the asserting of which channel deviates from the other. Similarly, the night/day biases evidenced for each pair of chan- 


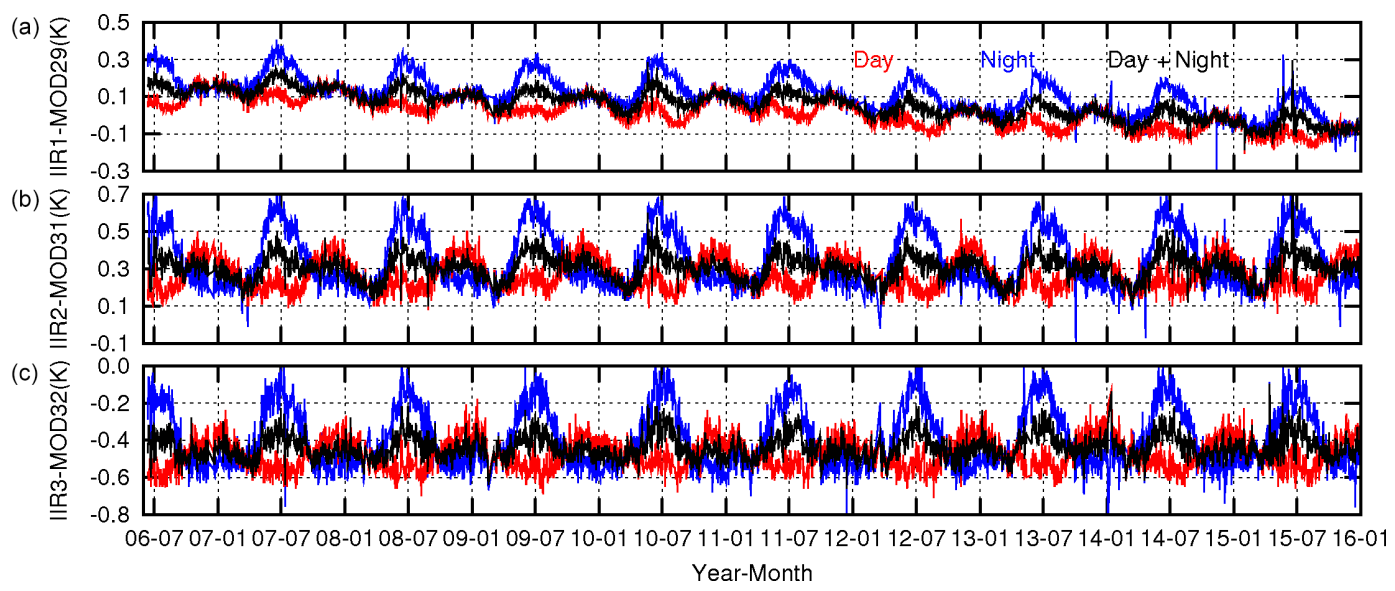

Figure 11. Time series ( $x$ axis: year-month) of IIR-MODIS brightness temperature differences ( $y$-axis units: Kelvin) for the three pairs of companion channels (a IIR1-MODIS29, b IIR2-MODIS31, c IIR3-MODIS32) over ocean at 30-60 N and 280-290 K. Red: day only, blue: night only, black: day and night.

nels in the Northern Hemisphere at $30-60^{\circ}$ (Sect. 5.2.4) are investigated.

\subsection{Results}

The fraction of clear sky IIR pixels over ocean is the largest in the tropics at $30^{\circ} \mathrm{S}-30^{\circ} \mathrm{N}$, with $20 \%$ of the ocean pixels on average at nighttime and $25 \%$ daytime. The slightly larger daytime fraction could be in part due to the smaller signal to noise ratio of the lidar signal and therefore to a reduced ability to detect clouds. Figure 13 shows the mean monthly residuals obtained over ocean in the tropics for IIR1 and MODIS29 (top), IIR2 and MODIS31 (middle), and IIR3 and MODIS32 (bottom) night and day. Each monthly value is obtained from typically $4 \times 10^{3}$ simulations. Linear regression lines with temporal origin at the beginning of the mission are also plotted, with slopes and intercepts given on each panel. The residuals are found between 0.2 and $0.6 \mathrm{~K}$, which is deemed reasonable, keeping in mind that they are sensitive to the auxiliary data (including the clear sky mask) and that the surface emissivity is made constant and equal to 0.98 for all channels. The standard deviations are found between 0.4 and $0.6 \mathrm{~K}$ for the IIR channels and between 0.5 and $0.7 \mathrm{~K}$ for the MODIS channels. Values from IIR and MODIS are comparable, showing the importance of uncertainties in ancillary inputs as compared to the instrumental noise. Using the Version 3 non-corrected IIR clear sky mask leads to significantly larger standard deviations, up to $1.2 \mathrm{~K}$. Moreover, these residuals are larger by about $0.5 \mathrm{~K}$, with season- and latitude-dependent biases, which is fully consistent with the presence of unwanted clouds and therefore too-cold observations in these supposedly clear sky data samples.

The IIR1 $(0.412 \mathrm{~K})$ and MODIS29 $(0.392 \mathrm{~K})$ residuals shown in Fig. 13 differ by only $0.02 \mathrm{~K}$ at the beginning of the mission, and IIR2 $(0.208 \mathrm{~K})$ and MODIS31 $(0.249 \mathrm{~K})$ residuals differ by only $0.04 \mathrm{~K}$. This indicates that for these pairs, the differences between the observations are well reproduced by the simulations, suggesting an excellent accuracy of the IIR calibration. However, the IIR3 residuals $(0.324 \mathrm{~K})$ are smaller than the MODIS32 residuals $(0.579 \mathrm{~K})$ by $-0.26 \mathrm{~K}$. Because residuals are differences between simulations and observations, this means that the simulated IIR3MODIS32 differences are smaller than the observed differences by $-0.26 \mathrm{~K}$.

\subsection{Further findings}

\subsubsection{IIR1-MODIS29 trend}

Similar temporal variations of the monthly residuals in Fig. 13, of the order of less than $0.1 \mathrm{~K}$, are seen for all the channels of the two instruments, indicating that they originate from the simulations rather than from the observations. The slope of the MODIS29 residuals, $-0.019 \mathrm{~K} \mathrm{yr}^{-1}$, is much larger than that of IIR $1,0.0017 \mathrm{~K} \mathrm{yr}^{-1}$, meaning that MODIS29 observations have increased with respect to the simulations at a rate of $+0.019 \mathrm{~K} \mathrm{yr}^{-1}$, whereas IIR 1 ones have barely changed. This is in perfect agreement with the decrease of IIR1-MODIS29 BTD at a rate of $-0.019 \mathrm{~K} \mathrm{yr}^{-1}$ seen in the relative approach at $290-300 \mathrm{~K}$ in the tropics. For the IIR2-MODIS31 and IIR3-MODIS32 pairs, the absence of a detectable trend in the relative approach suggests that none of these four channels has been drifting. As expected, the slopes of the four residuals are quasi-identical and do not exceed $-0.0037 \mathrm{~K} \mathrm{yr}^{-1}$. Overall, this indicates that the much larger slope of the MODIS29 residuals is driven by MODIS observations and not by the simulations. In conclusion, none of the IIR channels exhibit a detectable trend, whereas MODIS29 exhibits a positive trend of about $+0.019 \mathrm{~K} \mathrm{yr}^{-1}$ since the beginning of the CALIPSO mission. It is recalled that MODIS C5 products are used for this anal- 


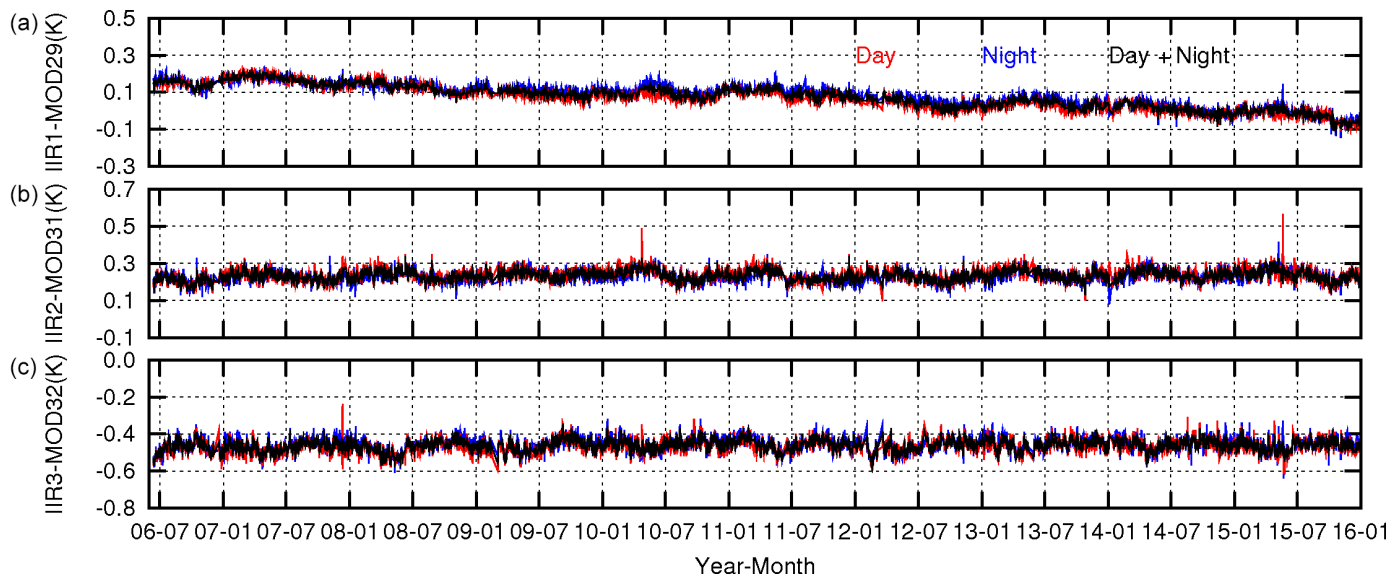

Figure 12. Same as Fig. 11, but at $60-30^{\circ} \mathrm{S}$.
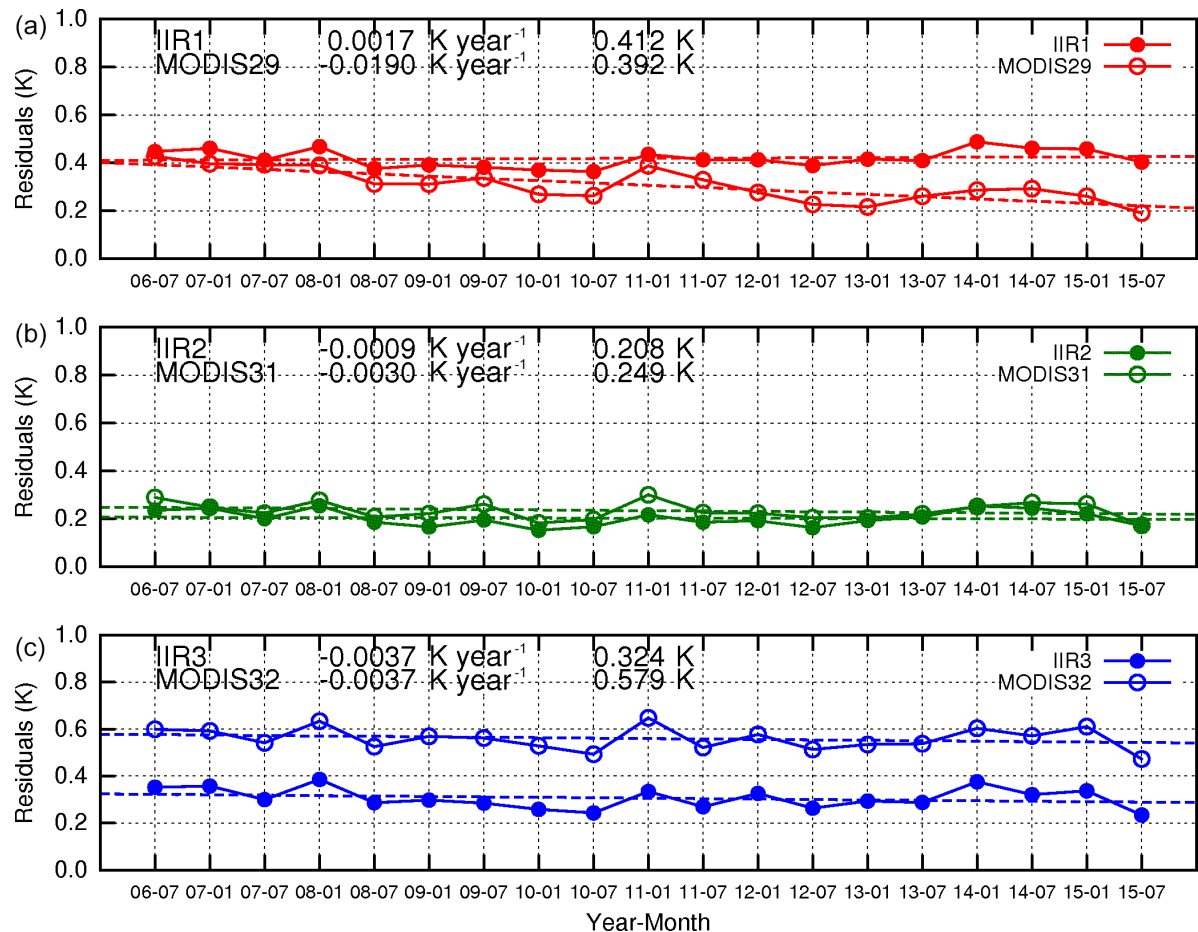

Figure 13. Time series ( $x$ axis: year-month) of residuals ( $y$-axis units: Kelvin) for the three pairs of IIR and MODIS channels (a IIR1 and MODIS29 in red, b IIR2 and MODIS31 in green, $\mathbf{c}$ IIR3 and MODIS32 in blue, with IIR in full circles and MODIS in open circles) over ocean in the tropics at $30^{\circ} \mathrm{S}-30^{\circ} \mathrm{N}$, day and night. Superimposed are linear regressions lines with temporal origin at the beginning of the mission. Slopes (in $\mathrm{K} \mathrm{yr}^{-1}$ ) and intercepts (in $\mathrm{K}$ ) are given on each panel.

ysis, so this assessment may not be applicable to the most recent Collection 6 (C6).

\subsubsection{IIR-MODIS night/day bias at $30-60^{\circ} \mathrm{N}$}

A night/day bias has been evidenced for each pair of IIRMODIS observations in the Northern Hemisphere at 30$60^{\circ}$, which varies seasonally and has its maximum amplitude in June and July (see Sect. 5.2.4 and Fig. 11). For fur- ther assessment, Fig. 14 shows the IIR and MODIS residuals for the three pairs of channels against latitude for the month of July 2007 by separating nighttime (top) and daytime (bottom) clear sky observations. Again, the results have to be interpreted in a relative sense. At night (top) and south of $25^{\circ} \mathrm{N}$, the IIR1 and MODIS29 residuals (red curves) and the IIR3 and MODIS32 residuals (blue curves) exhibit quasi-identical latitudinal variations, which are therefore attributed to the simulations. IIR2 and MODIS31 residuals 

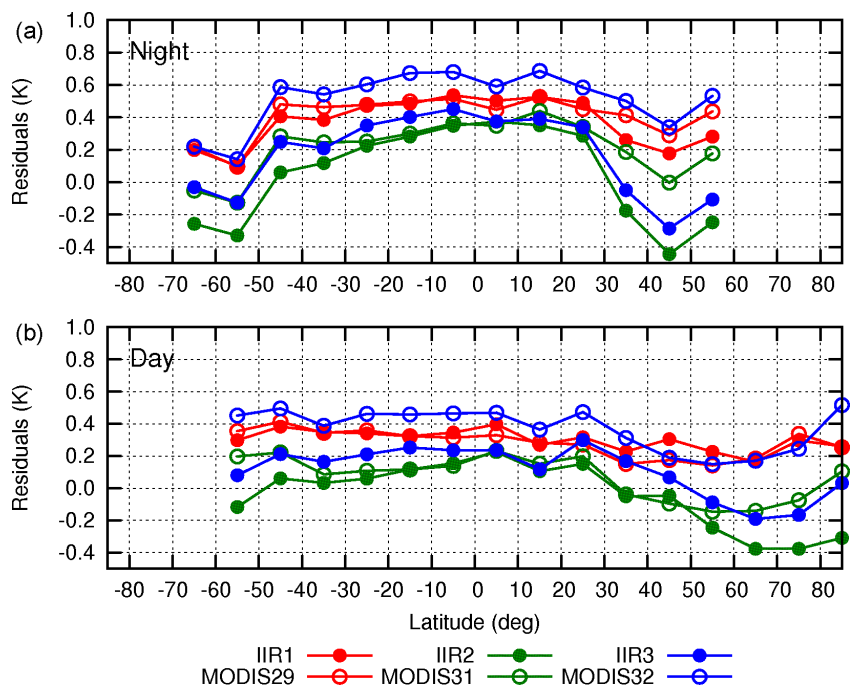

Figure 14. Residuals against latitude in July 2007 for the three pairs of IIR and MODIS channels (IIR1 and MODIS29: red, IIR2 and MODIS31: green, IIR3 and MODIS32: blue, IIR: full circles, MODIS: open circles). (a) Night. (b) Day.

(green curves) are very close from $35^{\circ} \mathrm{S}$ to $25^{\circ} \mathrm{N}$ and slightly depart from each other by up to $0.2 \mathrm{~K}$ south of $35^{\circ} \mathrm{S}$. Similar results are obtained during daytime (bottom) south of $25^{\circ} \mathrm{N}$. At night, from 25 to $45^{\circ} \mathrm{N}$, the three MODIS residuals (open circles) and the IIR1 residuals (red, full circle) have similar latitudinal variations, whereas IIR2 (green, full circle) and IIR3 (blue, full circle) residuals unambiguously decrease more rapidly than the others, by about $0.5 \mathrm{~K}$. However, during daytime, no distinct behavior of the IIR2 and IIR3 residuals is seen between 25 and $45^{\circ} \mathrm{N}$. The sudden decrease from 25 to $45^{\circ} \mathrm{N}$ seen for the IIR2 (respectively IIR3) nighttime residual, but not for the residual of its companion channel MODIS31 (respectively MODIS 32), indicates that this phenomenon originates from the observations. Furthermore, the fact that this sudden decrease is seen only for the IIR2 and IIR3 residuals and is seen at night but not during the day strongly suggests a calibration bias in IIR2 and IIR3 observations at night. A sudden decrease of the residuals means a sudden increase of the IIR 2 and IIR 3 brightness temperatures, by up to $0.5 \mathrm{~K}$ from about 30 to $45^{\circ} \mathrm{N}$. Thus, the stand-alone approach shows that the night-minus-day differences of $+0.4 \mathrm{~K}$ seen for IIR2-MODIS31 and IIR3MODIS32 in June and July in the Northern Hemisphere at $30-60^{\circ}$ (Fig. 11) using the relative approach are due to the fact that IIR2 and IIR3 channels are biased and too warm at night. It is recognized that the smaller night-day differences seen for IIR1-MODIS29 $(+0.2 \mathrm{~K})$ in Fig. 11 are not clearly evidenced from the stand-alone approach. No issue is evidenced in the Southern Hemisphere and south of $25^{\circ} \mathrm{N}$ from the stand-alone approach, which is consistent with the fact that nighttime and daytime IIR-MODIS BTDs at $60-30^{\circ}$ in the Southern Hemisphere are nearly identical (Fig. 12).
It is noted that south of $25^{\circ} \mathrm{N}$, all nighttime residuals tend to be larger than daytime ones, by about $0.2 \mathrm{~K}$. However, differences due to the clear sky mask are expected to lead to larger daytime residuals because of the a priori larger probability for the lidar to miss clouds during daytime. Thus, even though the clear sky mask may partly explain these differences, it is likely not the only contributor. Nevertheless, these small differences do not impact the previous discussion.

The IIR calibration biases evidenced at mid-latitude in the Northern Hemisphere are being investigated in collaboration with CNES. Our current understanding is that the rapidly changing thermal environment of the instrument at the end of the daytime portion and at the beginning of the nighttime portion of the orbits in the Northern Hemisphere would not be perfectly accounted for through the blackbody source used for the in-flight calibration. The flaw is synchronized with the elapsed time since the night-to-day transition along the orbit. Because the latitude of the night-to-day transition depends on the season, the flaw appears at season-dependent latitudes but always in the Northern Hemisphere (T. Trémas, personal communication, 2012), which in turn explains the observed seasonal variations at fixed latitudes $\left(30-60^{\circ} \mathrm{N}\right)$. These calibration biases are expected to impact the IIR1-IIR3 interchannel BTD by less than $0.2 \mathrm{~K}$ on average and to have no significant impact on IIR2-IIR3 on average.

\section{Summary and conclusions}

An assessment of the IIR calibration after 9.5 years of nearly continuous operation has been presented. IIR channels IIR1 $(8.65 \mu \mathrm{m})$, IIR2 $(10.6 \mu \mathrm{m})$, and IIR3 $(12.05 \mu \mathrm{m})$ have been primarily compared against MODIS/Aqua C5 companion channels MODIS29, MODIS31, and MODIS32, respectively, both on the A-Train with no instrumental changes since the CALIPSO launch. The choice of the companion instruments and channels was based on criteria such as spectral range and BTD between IIR and the candidate channels, quality and frequency of the spatial and temporal coincidences with the IIR $69 \mathrm{~km}$ swath, and spatial resolution. The BTD between IIR and its companion channels had been evaluated before launch using the $4 \mathrm{~A}$ radiative transfer model and five air mass types determined from the TIGR climatic data base (TIGR_BTD, Table 3). The simulation, collocation, and statistical tools have also been developed to perform comparisons with SEVIRI companion channels SEVIRI8.7, SEVIRI10.8, and SEVIRI12.

Two complementary approaches have been applied, which aim at characterizing deviations between the pairs of companion channels as well as the behavior of each individual channel both qualitatively and quantitatively. The relative approach is based on statistical analyses of BTD between IIR and the relevant companion channels in controlled conditions, over a wide range of brightness temperatures and over ocean. This approach uses only calibrated and geolocated 
radiances and does not require additional information from the lidar, such as the clear sky mask. The stand-alone approach is based on direct comparisons between simulations and observations (residuals) in clear sky conditions, using the 4A/OP model and inputs from time-space collocated ERAInterim reanalysis products. The clear sky mask is derived from the Version 3 IIR Level 2 swath product and has been corrected for this study to account for additional clouds detected by CALIOP at $1 / 3 \mathrm{~km}$ resolution but not accounted for in the current IIR operational algorithm. Overall, a remarkable stability of IIR with respect to MODIS companion channels is seen in the Southern Hemisphere and in the tropics since launch using the relative approach. No long-term trend could be detected for the IIR channels, MODIS31, and MODIS32. However, a trend of $-0.02 \mathrm{~K} \mathrm{yr}^{-1}$ on average is seen for IIR1-MODIS29 at any latitude. The complementary stand-alone approach showed that it originates from a long-term positive trend of MODIS29. A seasonal and systematic nighttime IIR calibration bias has been evidenced at mid-latitude in the Northern Hemisphere. It was first detected using the relative approach through surprising differences between nighttime and daytime IIR-MODIS BTDs and was further assessed by comparing latitudinal variations of MODIS and IIR residuals of the stand-alone approach for the month of July 2007 . The worst bias at $30-60^{\circ} \mathrm{N}$ is in June and July, where IIR 2 and IIR 3 night brightness temperatures are on average too large by $0.4 \mathrm{~K}$, and the IIR 1 temperatures are too large by $0.2 \mathrm{~K}$. IIR calibration with respect to MODIS has been assessed by comparing the residuals of the stand-alone approach for each pair of companion channels. In the tropics, IIR1 and MODIS29 residuals differ by less than $0.02 \mathrm{~K}$, and IIR2 and MODIS31 ones are within $0.04 \mathrm{~K}$. However, IIR3-MODIS32 BTDs are larger than simulated by $0.26 \mathrm{~K}$. This is deemed again a remarkable agreement when compared to the specifications for the IIR instrument (accuracy better than $1 \mathrm{~K}$ ). At the coldest temperatures (190-200 K), for which similar brightness temperatures are expected, each IIR channel is unambiguously warmer than its MODIS companion channel, by about $1.6 \mathrm{~K}$, whereas both IIR and MODIS inter-channel BTDs are close to zero, showing internal consistency within each instrument. This could be explained by a systematic bias in the IIR calibration at very cold temperatures. Initial comparisons between MODIS C5, used for this analysis, and the most recent C6 for several months in 2008 show little change at warm temperatures. However, MODIS31 and MODIS32 are colder in C6 than in C 5 by at least $1 \mathrm{~K}$ at $190-200 \mathrm{~K}$, so the internal consistency between the three MODIS channels is not seen in C6 at the coldest temperatures. A more detailed assessment for cloudy scenes will be conducted in the future using the description of the cloud vertical structure provided by CALIOP measurements and cloud microphysical models, following the same approach as in the IIR Level 2 algorithm (Garnier et al., 2012, 2013). The analysis will be carried out using both MODIS C5 and C6.
Overall, IIR on-orbit calibration over 9.5 years is excellent and very stable in the Southern Hemisphere and in the tropics, within specifications, showing no sign of instrumental aging. Corrections for the residual biases identified in the Northern Hemisphere are being developed in collaboration with CNES for implementation in a future version of the IIR Level 1B products. The monitoring of the IIR instrument will be continued in collaboration with AERIS/ICARE, will be updated as new versions of the IIR products become available, and will use MODIS C6. The stand-alone approach will be completed for every month since the CALIPSO launch using the corrected mask, which will be implemented in the next version (4) of the IIR Level 2 products. The clear sky simulations will be refined to include more accurate estimates of ocean surface emissivity.

It is believed that this assessment reinforces the value of the collocated IIR and CALIOP data record from the CALIPSO mission, which has now reached almost 11 years in orbit as part of the A-Train. This work is part of the efforts made in the international research community and space agencies (approximately 15 contributors in GSICS for these latter ones) to provide improved and consistent level 1 and level 2 products from various space-borne instruments for atmospheric science or climate monitoring.

Data availability. Post-processed satellite data are available upon request from the authors.

Competing interests. The authors declare that they have no conflict of interest.

Acknowledgements. The authors are deeply grateful to CNES, the NASA Langley Research Center, and SSAI (Science Systems and Applications, Inc.) for their support. This work benefited from the support of the Centre National de la Recherche Scientifique (CNRS) and of Institut National des Sciences de l'Univers (INSU).

Numerous people have contributed to this work over the years. The experience gained at the occasion of the NOAA/NASA Pathfinder Program and related research since then has paved the way for this study. Our warmest thanks go to Alain Chédin and colleagues from LMD for stimulating discussions at all the stages of this work. We thank Thérèse Barroso and Pascale Ferrage, former and current CNES CALIPSO mission coordinators, for their helpful discussions about the IIR instrument and the CALIPSO team for their encouragement. We thank Jacques Descloitres, JeanMarc Nicolas, and Fabrice Ducos from AERIS/ICARE for their assistance and Olivier Chomette (LMD) for his contribution at the early stage of this work.

We are thankful to Didier Renaut, Denis Blumstein, and Denis Jouglet from CNES for giving us the opportunity to present our results at the occasion of GSICS Meetings.

CALIPSO data are processed and available at the NASA Langley Research Center and are also available at the AERIS/ICARE data center. The REMAP product is processed and available at 
AERIS/ICARE. For the post-processing of the satellite data and for the archiving, we also benefited from the large facilities of the Institute for Development and Resources in Intensive Scientific computing (IDRIS) of CNRS and of the Ensemble de Services Pour la Recherche à l'IPSL (ESPRI)/AERIS data and computing center at IPSL. The authors are thankful to ECMWF for making the ERA-I outputs available through the ECMWF Data Server.

The authors thank the anonymous reviewers for their constructive and helpful comments.

Edited by: B. Kahn

Reviewed by: three anonymous referees

\section{References}

Achard, V.: Trois problèmes de l'analyse 3D de la structure thermodynamique de l'atmosphère par satellite: mesure du contenu en ozone; classification des masses d'air; modélisation "hyperrapide" du transfert radiatif, Thèse de doctorat en Terre, océan, espace, Paris 7 University, Paris, 1991.

Ackerman, S. A., Smith, W. L., Spinhirne, J. D., and Revercomb, H. E.: The 27-28 October 1986 FIRE IFO cirrus case study: Spectral properties of cirrus clouds in the $8-12 \mu \mathrm{m}$ window, Mon. Weather Rev., 118, 2377-2388, 1990.

Anthony Vincent, R. and Dudhia, A.: Fast radiative transfer using monochromatic look-up tables, J. Quant. Spectrosc. Ra., 186, 254-264, doi:10.1016/j.jqsrt.2016.04.011, 2017.

Armante, A., Scott, N. A., Crevoisier, C., Capelle, V., Crépeau, L., Jacquinet, N., and Chédin, A.: Evaluation of spectroscopic databases through radiative transfer simulations compared to observations. Application to the validation of GEISA 2015 with IASI and TCCON, J. Mol. Spectrosc., 327, 180-192, doi:10.1016/j.jms.2016.04.004, 2016.

Bériot, N., Scott, N. A, Chédin, A., and Sitbon, P.: Calibration of geostationary-satellite infrared radiometers using the Tiros-N vertical sounder: application to Meteosat-1, J. Appl. Meteor., 21, 84-89, doi:10.1175/15200450(1982)021<0084:COGSIR>2.0.CO;2, 1982.

Brown, O. B. and Minnett, P. J.: MODIS infrared sea surface temperature algorithm - Algorithm Theoretical Basis Document. Products: MOD28, ATBD Reference Number: ATBD-MOD-25, 1999.

Chédin, A., Scott, N. A., Wahiche, C., and Moulinier, P.: The improved initialization inversion method: a high-resolution physical method for temperature retrievals from satellites of the TIROS-N series, J. Clim. Appl. Meteorol., 24, 128-143, 1985.

Chédin, A., Fischer, H., Kunzi, K., Spankuch, D., and Scott, N. A.: ITRA (Intercomparison of Transmittance and Radiance Algorithms) campaigns and workshops. A report of the International Radiation Commission Joint Meeting ITRA- ICRCCM, University of Maryland, March 1986, 1988.

Chédin, A., Scott, N. A., Claud, C., Bonnet, B., Escobar-Munoz, J., Dardaillon, S., Cheruy, F., and Husson, N.: Global scale observation of the Earth for climate studies, Adv. Space Res., 14, 155-159, doi:10.1016/0273-1177(94)90364-6, 1994.

Chéruy, F., Scott, N. A., Armante, R., Tournier, B., and Chédin, A.: Contribution to the development of radiative transfer models for high spectral resolution observations in the infrared, J. Quant. Spectrosc. Ra., 53, 597-611, 1995.

Chevallier, F., Chéruy, F., Scott, N. A., and Chédin, A.: A neural network approach for a fast and accurate computation of longwave radiative budget, J. Appl. Meteorol., 37, 1385-1397, 1998.

Corlay, G., Arnolfo, M.-C. Bret-Dibat, T., Lifermann, A., and Pelon, J.: The Infrared Imaging Radiometer for PICASSO-CENA, CNES Tech. Doc., 14 pp., available at: https://calipso.cnes.fr/sites/default/files/migration/smsc/calipso/ IIR_ICSO00_S2-06.pdf, (last access 13 October 2016), 2000.

Dee, D. P., Uppala, S. M., Simmons, A. J., Berrisford, P., Poli, P., Kobayashi, S., Andrae, U., Balmaseda, M. A., Balsamo, G., Bauer, P., Bechtold, P., Beljaars, A. C. M., van de Berg, L., Bidlot, J., Bormann, N., Delsol, C., Dragani, R., Fuentes, M., Geer, A. J., Haimberger, L., Healy, S. B., Hersbach, H., Hólm, E. V., Isaksen, L., Kållberg, P., Köhler, M., Matricardi, M., McNally, A. P., Monge-Sanz, B. M., Morcrette, J.-J., Park, B.-K., Peubey, C., de Rosnay, P., Tavolato, C., Thépaut, J.-N. and Vitart, F.: The ERA-Interim reanalysis: configuration and performance of the data assimilation system, Q. J. Roy. Meteor. Soc., 137, 553-597, doi:10.1002/qj.828, 2011.

EUMETSAT: Typical radiometric accuracy and noise for MSG1/2, Rep. EUM/OPS/TEN/07/0314, 4 pp., Darmstadt, Germany, 2007a.

EUMETSAT: A planned change to the MSG Level 1.5 image product radiance definition, Rep. EUM/OPS-MSG/TEN/06/0519 issue v1A, Darmstadt, Germany, 9 pp., 2007b.

Garnier A., Pelon, J., Dubuisson, P., Faivre, M., Chomette, O., Pascal, N., and Kratz, D. P.: Retrieval of cloud properties using CALIPSO Imaging Infrared Radiometer, Part I: effective emissivity and optical depth, J. Appl. Meteorol. Climatol., 51, 14071425, doi:10.1175/JAMC-D-11-0220.1, 2012.

Garnier, A., Pelon, J., Dubuisson, P.,Yang, P., Faivre, M., Chomette, O., Pascal, N., Lucker, P., and Murray, T.: Retrieval of cloud properties using CALIPSO Imaging Infrared Radiometer, Part II: effective diameter and ice water path, J. Appl. Meteorol. Climatol., 52, 2582-2599, doi:10.1175/JAMC-D-12-0328.1, 2013.

GLOBE Task Team and Hastings, D. A., Dunbar, P. K., Elphingstone, G. M., Bootz, M., Murakami, H., Maruyama, H., Masaharu, H., Holland, P., Payne, J., Bryant, N. A., Logan, T. L., Muller, J.-P., Schreier, G., and MacDonald, J. S.: The Global Land One-kilometer Base Elevation (GLOBE) Digital Elevation Model, Version 1.0, National Oceanic and Atmospheric Administration, National Geophysical Data Center, 325 Broadway, Boulder, Colorado 80305-3328, USA, Digital data base on the World Wide Web, available at: http://www.ngdc.noaa.gov/mgg/ topo/globe.html (last access: 7 April 2017), 1999.

Goldberg, M., Ohring, G., Butler, J., Cao, C., Datla, R., Doelling, D., Gärtner, V., Hewison, T., Iacovazzi, B., Kim, D., Kurino, T., Lafeuille, J., Minnis, P., Renaut, D., Schmetz, J., Tobin, D., Wang, L., Weng, F., Wu, X., Yu, F., Zhang, P., and Zhu, T.: The global space-based inter-calibration system (GSICS), B. Am. Meteorol. Soc., 92, 468-475, 2011.

GSICS Global Space-based Inter-Calibration System: Vision of GSICS in the 2020s: shaping GSICS to meet future challenges, WMO/GSICS-RD002 v1.1, 12 pp., 2015.

Hanafin, J. A. and Minnett, P. J.: Measurements of the infrared emissivity of a wind-roughened sea surface, Appl. Opt., 44, 398-411, 2005. 
Hu, Y., Winker, D., Vaughan, M., Lin, B., Omar, A., Trepte, C., Flittner, D., Yang, P., Sun, W., Liu, Z., Wang, Z., Young, S., Stamnes, K., Huang, J., Kuehn, R., Baum, B., and Holz, R.: CALIPSO/CALIOP Cloud Phase Discrimination Algorithm, J. Atmos. Ocean. Technol., 26, 2293-2309, doi:10.1175/2009JTECHA1280.1, 2009.

Hunt, W., Winker, D., Vaughan, M., Powell, K., Lucker, P., and Weimer, C.: CALIPSO lidar description and performance assessment, J. Atmos. Ocean. Technol., 26, 1214-1228, 2009.

Inoue, T.: On the temperature and effective emissivity determination of semitransparent cirrus clouds by bi-spectral measurements in the $10 \mu \mathrm{m}$ window region, J. Meteorol. Soc. Jpn., 63, 88-98, 1985.

Jacquinet-Husson, N., Crépeau, L., Armante, R., Boutammine, C., Chédin, A., Scott, N. A., Crevoisier, C., Capelle, V., Boone, C., Poulet-Crovisier, N., Barbe, A., Campargue, A., Benner, D. Chris, Benilan, Y., Bézard, B., Boudon, V., Brown, L. R., Coudert, L. H., Coustenis, A., Dana, V., Devi, V. M., Fally, S., Fayt, A., Flaud, J.-M., Goldman, A., Herman, M., Harris, G. J., Jacquemart, D., Jolly, A., Kleiner, I., Kleinböhl, A., Kwabia-Tchana, F., Lavrentieva, N., Lacome, N., Xu, Li-Hong, Lyulin, O. M., Mandin, J.-Y., Maki, A., Mikhailenko, S., Miller, C. E., Mishina, T., Moazzen-Ahmadi, N., Müller, H. S. P., Nikitin, A., Orphal, J., Perevalov, V., Perrin, A., Petkie, D. T., Predoi-Cross, A., Rinsland, C. P., Remedios, J. J., Rotger, M., Smith, M. A. H., Sung, K., Tashkun, S., Tennyson, J., Toth, R. A., Vandaele, A.-C., and Vander Auwera, J.: The 2009 edition of the GEISA spectroscopic database, J. Quant. Spectrosc. Ra., 112, 2395-2445, doi:10.1016/j.jqsrt.2011.06.004, 2011.

Jouglet, D., Scott, N. A., Pernin, J., Crepeau, L., Armante, R., Ben Sassi, M., and Chédin, A.: Short performance status of IASI on MetOp-A and MetOp-B, Radiometric and spectral intercomparison of IASI, Validation of Level1c at LMD : An interactive intercalibration and stand-alone approaches for IASI on board MetopA and MetopB and IIR on board CALIPSO, GSICS meeting, 24-28 March 2014, EUMETSAT, Darmstadt, 2014.

Liu, Q. and Schmetz, J.: On the problem of an analytical solution to the diffusivity factor, Beitr. Phys. Atmos., 61, 23-29, 1988.

Luther, F. M., Ellingson, R. G., Fouquart, Y., Fels, S., Scott, N. A., and Wiscombe, W.: Intercomparison of Radiation Codes in Climate Models (ICRCCM): longwave clear sky results, B. Am. Meteorol. Soc., 69, 40-48, 1988.

Masuda K., Takashima, T., and Takayama, Y.: Emissivity of pure and sea waters for the model sea surface in the infrared window regions, Remote Sens. Environ., 24, 313-329, 1988.

Niclòs, R., Caselles, V., Coll, C., and Valor, E.: Determination of sea surface temperature at large observation angles using an angular and emissivity dependent split-window equation, Remote Sens. Environ., 111, 107-121, 2007.

Rodgers, C. D. and Walshaw, C. D.: The computation of the infrared cooling rate in planetary atmospheres, Q. J. Roy. Meteor. Soc., 92, 67-92, 1966.

Scott, N. A.: A direct method of computation of transmission function of an inhomogeneous gaseous medium: description of the method and influence of various factors, J. Quant. Spectrosc. Ra., 14, 691-707, 1974.
Scott, N. A.: Assessing CALIPSO IIR radiance accuracy via standalone validation and a GEO/LEO inter-calibration approach using MODIS/Aqua and SEVIRI/MSG, GSICS Quarterly, 3, available at: http://www.star.nesdis.noaa.gov/smcd/GCC/documents/ newsletter/GSICS_Quarterly_Vol3No3_2009.pdf, (last access 8 July 2016), 2009.

Scott, N. A. and Chedin, A.: A fast line-by-line method for atmospheric absorption computations: The Automatized Atmospheric Absorption Atlas, J. Appl. Meteorol., 20, 802-812, 1981.

Scott, N. A., Chédin, A., Armante, R., Francis, J., Stubenrauch, C., Chaboureau, J.-P., Chevallier, F., Claud, C., and Chéruy, F.: Characteristics of the TOVS Pathfinder Path-B data set, B. Am. Meteorol. Soc., 80, 2679-2701, 1999.

Stephens, G. L., Vane, D. G., Boain, R. J., Mace, G. G., Sassen, K., Wang, Z., Illingworth, A. J., O’Connor, E. J., Rossow, W. B., Durden, S. L., Miller, S. D., Austin, R. T., Benedetti, A., Mitrescu, C., and the CloudSat Science Team: The CloudSat mission and the A-Train: A new dimension of space-based observations of clouds and precipitation, B. Am. Meteorol. Soc., 83, 1771-1790, 2002.

Tinto, F. and Trémas, T.: IIR Level 1 Status, 2nd CALIPSO Exploitation Review, Norfolk (VA), USA, 2008.

Tournier, B., Armante, R., and Scott, N. A.: STRANSAC-93 et 4A-93: Développement et validation des nouvelles versions des codes de transfert radiatif pour application au projet IASI, Internal Rep. LMD, No. 201, LMD/CNRS, Ecole Polytechnique, Palaiseau, France, 1995.

Trémas, T.: Rapport de recette en vol - Radiométrie IIR-Calipso, CNES Tech. Doc CAL-IIR-RP-1189-CNES, Toulouse, France, 30 pp., 2006.

Turner, D. S.: Systematic errors inherent in the current modeling of the reflected downward flux term used by remote sensing models, Appl. Opt., 43, 2369-2383, 2004.

Vaughan, M., Pitts, M., Trepte, C., Winker, D., Detweiler, P., Garnier, A., Getzewitch, B., Hunt, W., Lambeth, J., Lee, K.-P , Lucker, P., Murray, T., Rodier, S., Trémas, T., Bazureau, A., and Pelon, J.: CALIPSO data management system data products catalog, document No. PC-SCI-503, Release 3.8, available at: http://www-calipso.larc.nasa.gov/products/CALIPSO_DPC_ Rev3x8.pdf (last access: 13 October 2016), 2015.

Winker, D. M., Pelon, J., Coakley Jr, J. A., Ackerman, S. A., Charlson, R. J., Colarco, P. R., Flamant, P., Fu, Q., Hoff, R., Kittaka, C., Kubar, T. L., LeTreut, H., McCormick, M. P., Megie, G., Poole, L., Powell, K., Trepte, C., Vaughan, M. A., and Wielicki, B. A.: The CALIPSO mission: A global 3D view of aerosols and clouds, B. Am. Meteorol. Soc., 91, 1211-1229, doi:10.1175/2010BAMS3009.1, 2010.

Wu, X. and Smith, W. L.: Sensitivity of sea surface temperature retrieval to sea surface emissivity, Acta Meteorol. Sin., 10, 3763-84, 1996.

Xiong, X., Wu, A., Wenny, B. N., Madhavan, S., Wang, Z., Li, Y., Chen, N., Barnes, W. L., and Salomonson, V. V.: Terra and Aqua MODIS thermal emissive bands on-orbit calibration and performance, IEEE T. Geosci. Remote, 53, 5709-5721, doi:10.1109/TGRS.2015.2428198, 2015. 